$\frac{3}{1 / 2} / 293950$

PPPL-2893

- UC-426

\section{PREPARED FOR THE U.S. DEPARTMENT OF ENERGY,} UNDER CONTRACT DE-AC02-76-CHO-3073

PPPL-2893

\title{
X-RAY DIAGNOSTICS OF TOKAMAK PLASMAS
}

BY

M. BITTER, H. HSUAN, K.W. HILL AND M. ZARNSTORFF

APRIL, 1993

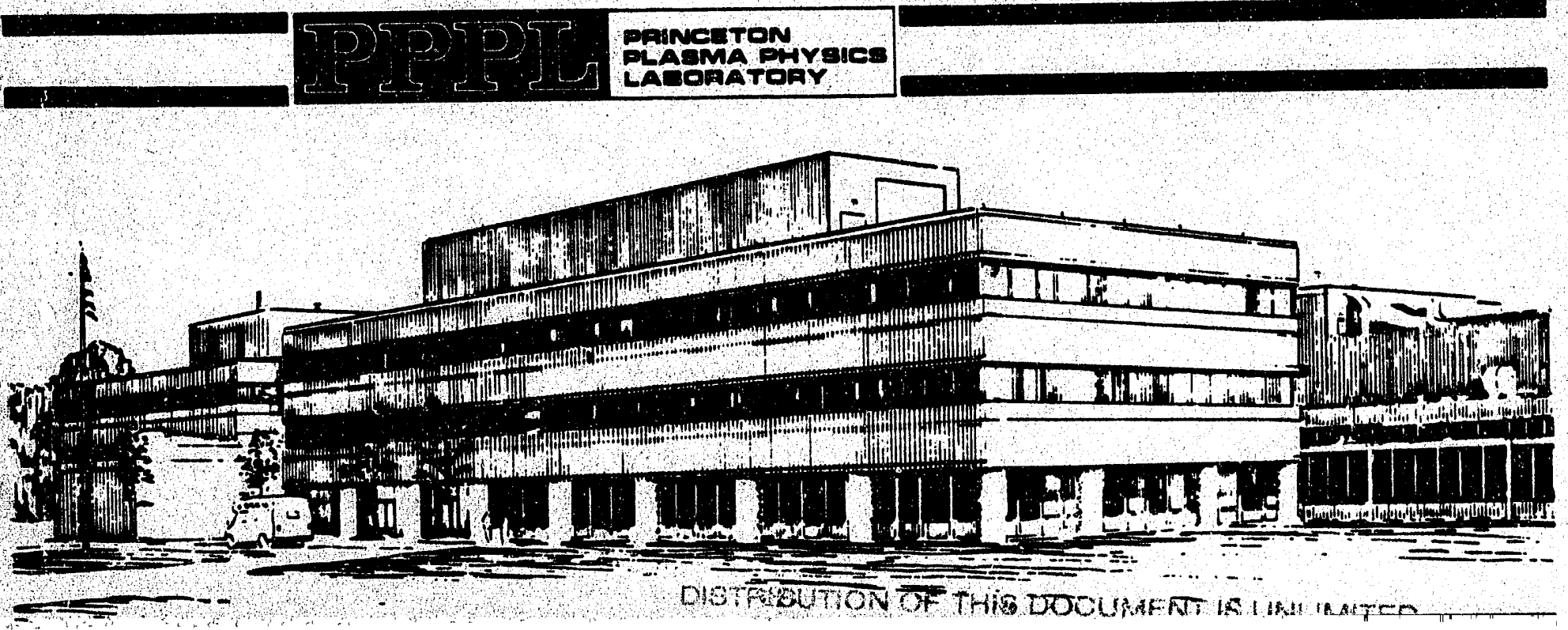




\section{NOTICE}

This report was prepared as an account of work sponsored by an agency of the United States Government. Neither the United States Government nor any agency thereof, nor any of their employees, makes any warranty, express or implied, or assumes any legal liability or responsibility for the accuracy, completeness, or usefulness of any information, apparatus, product, or process disclosed, or represents that its use vould not infringe privately owned rights. Reference herein to any specific commercial produce, process, or service by trade name, trademark, manufacturer, or othenwise, does not necessarily constitute or imply its endorsement, recommendation, or favoring by the United States Government or any agency thereof. The views and opinions of authors expressed herein do not necessarily state or reflect those of the United States Government or any agency thereof.

\section{NOTICE}

This report has been reproduced from the best available copy. Available in paper copy and microfiche.

Number of pages in this report: 34

DOE and DOE contractors can obtain copies of this report from:

Office of Scientific and Technical Information

P.O. Box 62

Oak Ridge, TN 37831;

(615) $576-8401$.

This report is publicly available from the:

National Technical Information Service

Department of Commerce

5285 Port Royal Road

Springfield, Virginia 22161

(703) $487-4650$ 


\title{
X-Ray Diagnostics of Tokamak Plasmas
}

\author{
M. Bitter, H. Hsuan, K. W. Hill, and M. Zarnstorff
}

Princeton University

Plasma Physics Laboratory

Princeton, NJ 08543

Presented at the 4th International Colloquium on Atomic Spectra and Oscillator Strengths for Astrophysical and Laboratory Plasmas, Septmeber 14 - 17, 1992 National Institute of Standards and Technology (NIST)

Gaithersburg , Md 20899 ,USA

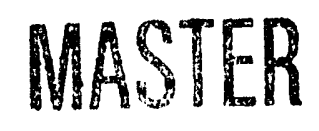




\begin{abstract}
The paper describes the X-ray diagnostics of central plasma parameters of present large tokamak fusion experiments by means of Johann type curved crystal spectrometers. These spectrometers have a very high spectral resolution, $\lambda / \Delta \lambda>10000$, and are mainly used to determine the central ion temperature from Doppler broadening measurements of the $1 \mathrm{~s}-2 \mathrm{p}$ resonance lines of high-Z heliumlike ions. The full diagnostic potential of the spectra of heliumlike ions is demonstrated by the detailed analysis of FeXXV satellite spectra from a particular high temperature tokamak discharge with reactor-like conditions. This analysis is based on least squares fit comparisons of the experimental data with synthetic spectra, which are constructed from theoretical predictions. It is found that the satellite spectra which are associated with the heliumlike resonance lines are in excellent agreement with the theoretical predictions. The satellite spectra can therefore be used for electron temperature measurements, measurements of the dielectronic recombination rate coefficients and the determination of relative ion charge-stace abundances. Discrepancies between experiment and theory are, however, observed for the intensity ratios of the heliumlike lines. Also discussed are atomic physics data needs and the potential of the X-ray diagnostic for future large tokamaks, such as ITER.
\end{abstract}




\section{Introduction}

$\mathrm{X}$-ray diagnostics of tokamak plasmas have become very important during the last decade due to the fact that these plasmas have achieved fusion-reactorlike experimental conditions with high temperatures of the order of $10 \mathrm{keV}$. Heliumlike ions of high- $\mathrm{Z}$ elements can be produced in the hot core of these plasmas, and spectra of ArXVII ${ }^{1,2}, \operatorname{TiXXI}^{3-5}, \operatorname{CrXXIII} 6,7, \operatorname{FeXXV}{ }^{8,9}$ and NiXXVI ${ }^{10-13}$ are now widely used to determine the certral plasma parameters. The main diagnostic application is the measurement of the central ion temperature, $\mathrm{T}_{\mathrm{i}}(0)$, from the Doppler widths of the emitted X-ray lines, which requires crystal spectrometers of very high spectral resolution, $\lambda / \Delta \lambda \geq$ 10000. The obtained high-resolution spectra are well suited for a detailed comparison with theoretical predictions due to the fact that tokamak plasmas are in steady state for durations of several seconds and are well-diagnosed by independent measurements of plasma parameters, such as the electron density and the electron temperature. Since the spectra of heliumlike ions are also used for the study of solar flares, very accurate theoretical calculations of these spectra have been performed for the elements with $\mathrm{Z} \leq 45.3,14-19$ The spectra consist of the heliumlike lines $w: 1 \mathrm{~s}^{2}{ }^{1} \mathrm{~S}_{0}-1 \mathrm{~s} 2 \mathrm{p}{ }^{1} \mathrm{P}_{1}$, $\mathbf{x}: 1 \mathrm{~s}^{2}{ }^{1} \mathrm{~S}_{0}-1 \mathrm{~s} 2 \mathrm{p}{ }^{3} \mathrm{P}_{2}, \mathbf{y}: 1 \mathrm{~s}^{2}{ }^{1} \mathrm{~S}_{0}-1 \mathrm{~s} 2 \mathrm{p}{ }^{3} \mathrm{P}_{1}$, and $\mathbf{z}: 1 \mathrm{~s}^{2}{ }^{1} \mathrm{~S}_{0}-1 \mathrm{~s} 2 \mathrm{~s}{ }^{3} \mathrm{~S}_{1}$ and the associated dielectronic and 'collisionally excited' satellites which are due to lithiumlike transitions of the type $1 \mathrm{~s}^{2} \mathrm{nl}-1 \mathrm{~s} 2 \mathrm{pnl}$ with $\mathrm{n} \geq 2$. The intensity ratios of the satellites and the resonance line $w$ provide important additional diagnostic information. They can be used for measurement of the central electron temperature ar:t determination of the ion charge state distribution. We point out that the experimental verification of theoretical predictions for the spectra of the heliumlike ions is important to establish a solid base for the theoretical calculations of the more complex ions. It is the purpose of this paper to review the atomic physics results from present tokamak experiments and to discuss the prospects of $\mathrm{X}$-ray diagnostics on future large tokamaks.

The paper is organized as follows: Section II describes the experimental parameters and X-ray crystal spectrometers of the Tokamak Fusion Test Reactor (TFTR), which is one of the present large tokamak experiments. Section III presents the analysis of two spectra of heliumlike iron from a particular TFTR discharge to demonstrate the importance of heliumlike spectra for the diagnostic of tokamak plasma parameters and to show a comparison of the observed spectra with theoretical predictions. In section IV we review atomic physics results from present tokamak experiments, and in section $\mathrm{V}$ we discuss the potential of $\mathrm{x}$-ray spectroscopy for the diagnostics of future large tokamaks. Conclusions are presented in section VI.

\section{Crystal Spectrometers on Tokamak Experiments}

The objective of the present large tokamak experiments is to study deuterium and deuterium-tritium plasmas under reactorlike conditions. The major tokamak experiments are the Joint European Torus (JET), the Japanese Tokamak JT-60, the French Tore Supra, and the US Tokamak 
Fusion Test Reactor (TFTR). A schematic (one half of a vertical cross-section) of TFTR is shown in Fig. 1. The plasma is magnetically confined by toroidal and poloidal fields, and it is ohmically heated by an induced toroidal current which is in the range from 0.5 to $2.2 \mathrm{MA}$. Since ohmic heating is not efficient at high temperatures, auxiliary plasma heating is provided by the injection of 12 energetic $(120 \mathrm{keV})$ neutral deuterium beams with a total power up to $35 \mathrm{MW}$ and by radio frequency (ion cyclotron) heating with input powers up to $12 \mathrm{MW}$. Table I lists the experimental parameters of TFTR. The plasma contains small amounts $\left(10^{-5}-10^{-3} \mathrm{~N}_{\mathrm{e}}\right.$, where $\mathrm{N}_{\mathrm{e}}$ is the electron density) of metal impurities, such as $\mathrm{Ti}, \mathrm{Cr}, \mathrm{Fe}$ and $\mathrm{Ni}$, which are ionized to different charge states. The radiation emitted from these metal impurity ions at the higher concentrations can represent a significant fraction of the total radiative power loss from the plasma. Therefore, every effort is made to reduce the amount of these impurities. On the other hand, the line radiation of these metal ions provides invaluable diagnostic information.

Figure 1 also shows the experimental arrangement of six crystal spectrometers which are used for Doppler broadening measurements. 20,21 These spectrometers are Johann type curved crystal spectrometers with a high spectral resolution, $\lambda / \Delta \lambda \geq 10000$. The crystal curvature radii are in the range from 3.8 to $12 \mathrm{~m}$. The spectrometers have one horizontal sightline in the midplane and five nearly vertical sightlines at different major radii to measure radial profiles of the ion temperature. The detectors have to be shielded against neutron and gamma radiation. The Johann configuration offers the advantages that (1) the heliumlike lines and the associated satellites can be simultaneously observed and (2) each spectral line is reflected from the entire crystal. Thus, since the resonance line and the satellites are observed under the same experimental conditions, their intensity ratios can be determined very accurately. The statistical errors of the spectral data are small due to the high throughput of the instruments.

Although plasma diagnostics generally rely on indigenous metal impurities, such as $\mathrm{Ti}, \mathrm{Cr}, \mathrm{Fe}$ and $\mathrm{Ni}$, other elements have been introduced into tokamak plasmas by laser evaporation or by gas puffs. These techniques were used by the TFR group to study the Z-dependent wavelength shifts and satellite line intensities in the spectra of the heliumlike ions. Figure 2 presents spectra of argon, scandium, vanadium, chromium and manganese, obtained from these experiments. 22 The spectra show a characteristic charge-dependent wavelength shift which is ascribed to the $Z^{4}$ dependence of the spin orbit interaction energy. Further documentation of these effects has been obtained from TFTR experiments by observation of the heliumlike spectra of titanium, chromium, iron and nickel. 21 We note that the spectral features are well separated in the heliumlike spectra of ions with $\mathrm{Z}$ $=24-26$, and that these spectra are therefore most appropriate for diagnostic applications. Figure 3 represents the fractional ion charge state abundances of iron as a function of the electron temperature for coronal equilibrium conditions. ${ }^{23}$ Heliumlike iron is the dominant charge state for electron temperatures in the range from 1.5 to $7 \mathrm{keV}$ and is therefore well suited for the diagnostics of central TFTR plasma parameters. 
III. Analysis of the satellite spectra of heliumlike ions

In this section we describe the detailed analysis of two FeXXV spectra which were obtained from a TFTR deuterium plasma with ohmic heating of $1 \mathrm{MW}$ and auxiliary heating of 20 MW by injection of neutal deuterium beams. The analysis is based on a detailed comparison of the observed spectra with synthetic spectra which were constructed from theoretical predictions. 15,18 The data were recorded by the TFTR horizontal crystal spectrometer, which collects $128 \mathrm{FeXXV}$ satellite spectra per discharge with a time resolution of $50 \mathrm{~ms}$. Figure 4 shows the ion temperature results from Doppler broadening measurements of the $1 \mathrm{~s}-2 \mathrm{p}$ resonance line. The ion temperature increased from 2.5 to $28 \mathrm{keV}$ during the period of the deuterium beam injection from 3 to $4 \mathrm{sec}$. Figure 5 presents the observed time evolution of the central electron temperature and electron density from measurements of the electron cyclotron emission and by far-infrared laser interferometry, respectively. Both the ions and the electrons were heated very efficiently for the given experimental conditions. This type of tokamak discharge also provides high yields $\left(-5 \times 10^{16} \mathrm{sec}^{-1}\right)$ of $2.5 \mathrm{MeV}$ neutrons from D-D fusion reactions and will most likely be used for the final D-T experiments on TFTR.

Figures 6 and 7 present two observed FeXXV satellite spectra and synthetic spectra, which represent least squares fits of theoretical predictions to the experimental data. The observed spectra are accumulated spectra covering periods of steady state conditions, i. e. the time of ohmic heating from 2.5 to $3 \mathrm{sec}$ and the time from 3.5 to $4 \mathrm{sec}$ with the injection of deuterium beams, when the parameters $n_{e}, T_{e}$, and $T_{i}$, had again reached steady state conditions (see Figs. 4 and 5 ). Due to the accumulation of data over these extended periods, the statistical errors are substantially reduced. The synthetic spectra consist of the heliumlike lines $w, x, y$ and $z$, and the lithiumlike (and berylliumlike) satellites due to transitions $1 s^{2} n l-1 s 2 p n l$ with $n \geq 2$. The main spectral features have been identified by key letters following Gabriel's notation ${ }^{14}$ and are explained in Table II.The heliumlike lines are mainly produced by electron impact excitation from the heliumlike ground state, whereas the satellites can be produced in the process of dielectronic recombination of the heliumlike ions and/or by electron impact (inner-shell) excitation from the ground state of the lithiumlike (and berylliumlike) ions. The relative contributions from these two processes are different for different satellites. The satellites $\mathbf{k}$ and $\mathbf{j}$ are produced by dielectronic recombination, whereas the so-called 'collisional' satellites $\mathbf{q}, \mathbf{r}$, and $\mathbf{t}$ with transitions involving the lithiumlike ground state, have strong contributions from the process of inner-shell excitation. In addition to the features listed in Tabe! II, the synthetic spectra also include numerous $n \geq 3$ satellites which are of pure dielectronic nature.

Expressions for the emissivities, $\varepsilon$, of the different spectral components are given in an abbreviated form below (see Reference 15 for a detailed description): 
(1) heliumlike lines (w, $\mathbf{x}, \mathbf{y}, \mathbf{z})$ :

$$
\varepsilon_{\mathrm{w}, \mathrm{x}, \mathrm{y}, \mathrm{z}}=\langle\sigma \mathrm{v}\rangle_{\mathrm{w}, \mathrm{x}, \mathrm{y}, \mathrm{z}} \mathrm{N}_{\mathrm{e}} \mathrm{N}_{\mathrm{He}}
$$

(2) 'collisional' satellites:

$$
\varepsilon_{\text {c.s. }}=\langle\sigma v\rangle_{\text {c.s. }} \mathbf{N}_{\mathbf{e}} \mathbf{N}_{\mathbf{L i}}\left(\text { or } \mathrm{N}_{\mathrm{Be}}\right)
$$

(3) 'dielectronic' satellites:

$$
\varepsilon_{\text {d.s. }}=\mathrm{I}_{1}\left(\mathrm{~T}_{\mathrm{e}}\right) \mathrm{F}_{2}(\mathrm{~s}) \mathrm{N}_{\mathrm{e}} \mathrm{N}_{\mathrm{He}}
$$

$\mathrm{N}_{\mathrm{e}}, \mathrm{N}_{\mathrm{He}}, \mathrm{N}_{\mathrm{Li}}$ and $\mathrm{N}_{\mathrm{Be}}$ are, respectively, the electron density and the densities of the heliumlike, lithiumlike and berylliumlike charge states. $\langle\sigma v\rangle$ is the excitation rate coefficient for electron impact excitation for the case of a Maxwellian electron energy distribution. $F_{1}\left(T_{e}\right)=$ $\left(2 \pi \mathrm{h} / \mathrm{mk} \mathrm{T}_{\mathrm{e}}\right)^{3 / 2} \exp \left(-\mathrm{E}_{\mathrm{S}} / \mathrm{T}_{\mathrm{e}}\right)$, where $E_{\mathrm{S}}$ is the energy difference between the excited lithiumlike state, 1s2pnl, and the $1 s^{2}$ heliumlike grourd state. $F_{2}(s)=g_{\delta} / g_{1} A_{r} s A_{a} s i^{\prime}\left(\Sigma^{\prime} A_{a} s i^{\prime}+\Sigma A_{r} s f^{\prime}\right)$ is the satellite line strength; $g_{s}$ and $g_{1}$ are the statistical weights of the excited lithiumlike state and the heliumlike ground state, respectively; and $\mathrm{A}_{\mathrm{a}} \mathrm{si}$ and $\mathrm{A}_{\mathrm{r}} \mathrm{sf}$ are the probabilities for autoionization and radiative transitions from the $1 \mathrm{~s} 2 \mathrm{pnl}$ state.

It follows from the expressions (1), (2) and (3), that the intensity ratios of the 'collisional' satellites and the heliumlike resonance line $w$ are directly proportional to the relative abundances, $\mathrm{N}_{\mathrm{Li}} / \mathrm{N}_{\mathrm{He}}$ and $\mathrm{N}_{\mathrm{Be}} / \mathrm{N}_{\mathrm{He}}$, since $\langle\sigma v\rangle_{\mathrm{w}}$ and $\langle\sigma v\rangle_{\text {c.s. }}$, have approximately the same $\mathrm{T}_{\mathrm{e}}$ dependence ${ }^{15}$, and that the intensity ratios of the 'dielectronic' satellites and the resonance line $\mathbf{w}$ are only a function of the electron temperature. The synthetic spectra depend therefore on only four parameters: $\mathrm{T}_{\mathrm{e}}, \mathrm{N}_{\mathrm{Li}} / \mathrm{N}_{\mathrm{He}}, \mathrm{N}_{\mathrm{Be}} / \mathrm{N}_{\mathrm{He}}$, and the ion temperature $\mathrm{T}_{\mathrm{i}}$, which determines the width of the spectral lines. The synthetic spectra shown in Figs. 6 and 7 represent least squares fits of the theoretical predictions to the experimental data with respect to these four parameters. The results are listed in Table III. The details of the least squares fitting procedure, which involves several steps, have been described earlier. 13

For an experimental verification of the theory it is necessary to compare the parameter values of $\mathrm{T}_{e}, \mathrm{~N}_{\mathrm{Li}} / \mathrm{N}_{\mathrm{He}}$ and $\mathrm{N}_{\mathrm{Be}} / \mathrm{N}_{\mathrm{He}}$ in Table III with results from independent electron-temperature measurements and coronal-equilibrium calculations. In the spectrum shown in Fig. 6, the contributions from the various spectral components are clearly distinguishable due to the fact that the satellite intensities are appreciable for electron temperatures of $3 \mathrm{keV}$ and that the Doppler width for an ion temperature of $2.5 \mathrm{keV}$ is smaller than the separation of the main spectral fei.tures. The errors obtained foi the parameters $\mathrm{T}_{e}, \mathrm{~N}_{\mathrm{Li}} / \mathrm{N}_{\mathrm{He}}$ and $\mathrm{N}_{\mathrm{Be}} / \mathrm{N}_{\mathrm{He}}$ from the least squares fit method are therefore small. The value for the electron temperature, $\mathrm{T}_{\mathrm{e}}=3.24 \pm 0.04 \mathrm{keV}$, in Table III is in good agreement with the electron temperature measurements during the ohmic heating phase (see Fig. 5). However, the relative abundances, $\mathrm{N}_{\mathrm{Li}} / \mathrm{N}_{\mathrm{He}}=0.376 \pm 0.012$ and $\mathrm{N}_{\mathrm{Be}} / \mathrm{N}_{\mathrm{He}}=0.144 \pm 0.013$, in Table III are larger than the coronal-equilibrium values $\mathrm{N}_{\mathrm{Li}} / \mathrm{N}_{\mathrm{He}}=$ 
0.186 and $\mathrm{N}_{\mathrm{Be}} / \mathrm{N}_{\mathrm{He}}=0.022$ (see Fig. 3). The spectrum shown in Fig. 7 seems, at first sight, to have less structural detail than the spectrum shown in Fig. 6 . This is due to the fact that the satellite intensities are very much reduced for electron tempertures of $8 \mathrm{keV}$ and that the spectral features are smeared oút as a result of the large Doppler broadening obtained for ion temperatures of 20 $\mathrm{keV}$. The least squares fit method made it nevertheless possible to detect the very small intensity contributions of the dielectronic satellites and to derive from these contributions an electron temperature value of $\mathrm{T}_{\mathrm{e}}=8.2 \mathrm{keV} \pm 0.4 \mathrm{keV}$, which is in excellent agreement with the central electron temperature obtained from the laser Thomson scattering diagnostic (see Fig. 8). This agreement indicates that the observed radiation originates mainly from the hot core of the plasma, even though the data represent chord-integrated measurements along a horizontal sightline through the plasma (see Fig. 1). We may therefore conclude that the measured ion temperature value is the central ion temperature $\mathrm{T}_{\mathrm{i}}(0)$. It is evident from Fig. 7, that the 'collisional' satellites are much stronger than the dielectronic satellites. In fact, the relative abundances, $\mathrm{N}_{\mathrm{Li}} / \mathrm{N}_{\mathrm{He}}=0.260 \pm 0.008$ and $\mathrm{N}_{\mathrm{Be}} / \mathrm{N}_{\mathrm{He}}=0.018 \pm 0.005$, in Table III are much larger than the coronal-equilibrium values, $\mathrm{N}_{\mathrm{Li}} / \mathrm{N}_{\mathrm{He}}=0.047$ and $\mathrm{N}_{\mathrm{Be}} / \mathrm{N}_{\mathrm{He}}<0.01$ for an electron temperature of $8 \mathrm{keV}$. This enhancement of $\mathrm{N}_{\mathrm{Li}} / \mathrm{N}_{\mathrm{He}}$ and $\mathrm{N}_{\mathrm{Be}} / \mathrm{NHe}_{\mathrm{He}}$ is ascribed to charge-exchange recombination of the FeXXV and FeXXIV ions with the injected deuterium atoms. The intensity ratios, $x / w, y / w$ and $z / w$, of the heliumlike lines are found to be larger than the ratios obtained from Eq. (1) which only accounts for the direct excitation from the heliumlike ground state. 15 In our least squares fit procedure, we introduced the qantities $x a$, ya and $z a$, which measure the enhancement of $x / w, y / w$ and $z / w$ over the predictions from Eq. (1). The observed ratios of the heliumlike lines will be further discussed in the next section.

\section{Review of experimental Results.}

In this section we review the atomic physics results from the X-ray spectroscopy of tokamak plasmas and discuss the contributions from the different spectral components separately.

\section{A. Measurements of Dielectronic recombination rate coefficients.}

Data on dielectronic recombination rate coefficients are needed for plasma modeling calculations to determine the ionization equilibria of high- $Z$ ions in solar flares and in fusion plasmas. However, it is very difficult to measure these rate coefficients. Standard techniques which use crossed-beam methods suffer from the lack of suitable ion beams and are limited to low-ionization states. Data on rate coefficients for high- $Z$ ions were therefore mainly obtained from plasma experiments by indirect methods based on observations of the line radiation from successive charge states. The interpretation of these experimental data depends on extensive modeling of the charge state distribution, so that the uncertainties for the derived rate coefficients are often large. Only recently, due to the development of Electron Beam Ion Traps (EBIT), has it become possible to perform reliable measurements of rate coefficients of high- $\mathrm{Z}$ ions, such as 
NiXXVII. ${ }^{24}$ It is thus fortunate that the dielectronic satellite spectra of the $1 \mathrm{~s}-2 \mathrm{p}$ resonance lines offer an opportunity to determine the dielectronic rate coefficients for high- $\mathrm{Z}$ heliumlike and hydrogenlike ions. The method, which was first proposed by Bely-Dubau et al. ${ }^{25}$, is independent of plasma modeling and involves only the single-charge state of interest. Following Bely-Dubau et al., the total dielectronic recombination rate coefficient associated with the $1 \mathrm{~s}-2 \mathrm{p}$ core transition of heliumlike ions can be obtained from measurements of the sum of the intensity ratios of the dielectronic satellites and the resonance line, $\Sigma \mathrm{I}_{\mathrm{d}} / \mathrm{I}_{\mathrm{W}}$, using the expression

$$
\alpha_{\mathrm{d}}=\langle\sigma v\rangle_{\mathrm{w}} \Sigma \mathrm{I}_{\mathrm{d}} / \mathrm{I}_{\mathrm{w}}
$$

where the collisional excitation rate coefficient for the resonance line $w,\langle\sigma v\rangle_{w}$, is assumed to be known. Figure 9 shows the results for the dielectronic recombination rate coefficients of FeXXV, which were obtained by this method from tokamak experiments. ${ }^{26}$ The data are in good agreement with the theory of Bely-Dubau et al. 15,25 , as one may expect from the discussion of the dielectronic satellite spectra given in the previous section. Further results on the dielectronic rate coefficients of heliumlike and hydrogenlike $\mathrm{Ti}, \mathrm{Cr}$ and $\mathrm{Ni}$ are given in Reference 27 . We note that experimertal results on the dielectronic recombination of heliumlike nickel NiXXVI from tokamak experiments are in good agreement with those obtained by Knapp et al.. 24

\section{B Comparison of the ion charge state distributions with coronal equilibrium calculations}

As discussed in the previous section, it is possible to determine the relative abundances, $\mathrm{N}_{\mathrm{Li}} / \mathrm{N}_{\mathrm{He}}$ and $\mathrm{NBe}_{\mathrm{Be}} / \mathrm{N}_{\mathrm{He}}$, of the heliumlike, lithiumlike and berylliumlike charge states from the intensity ratios of the 'collsional' satellites and the resonance line $w$. If radial ion transport is negligible, these relative ion abundances are expected to be in agreement with coronal equilibrium. This is due to the fact that the densities in tokamak plasmas, which are of the order of $\mathrm{N}_{\mathrm{e}} \sim 10^{13}$ $-10^{14} \mathrm{~cm}^{-3}$, correspond to ...e so-called zero density limit for ions with $Z>20$, so that the high- $Z$ ions are in their ground states. Moreover, the ionization and recombination times are small compared with the times of steady state conditions, so that the charge state distribution reaches an ionization equilibrium. Effects of radial ion transport can, however, lead to a shift of the ionization equilibrium in the hot core of tokamak plasmas towards lower charge states. These effects can thus be determined by measuring the deviations from coronal equilibrium. A quantitative analysis requires, in general, detailed modeling calculations which include radial profile effects of the electron temperarure and density and which must primarily be based on reliable coronal equilibrium predictions. Improved coronal equilibrium predictions for the ion charge states of nickel have recently been provided by Zastrow et al. 12 and have been compared with experimental data from JET 12 and TFTR. 13 The JET data were obtained from a great number of discharges with very different electron density and electron temperature profiles. These data were analyzed by 
cornparing the observed line intensities with modeling calculations of chord-integrated line emissivities along the spectrometer sightline through the plasma. It was found that the observed line intensities were within the bounds of the coronal equilibrium predictions for the given range of radial profiles. On the other hand, the TFTR data were obtained from a special series of ohmically heated helium plasmas $w^{i}$ th very flat radial profiles of the electron density and electron temperature. The observed spectra were therefore essentially emitted from plasmas with well-defined single values of the electron density and electron temperature. Thus, it was justified to neglect radial profile effects and to compare the observed spectra with synthetic spectra for single values of the parameters $T_{e}, T_{i}, N_{L i} / N_{H e}$ and $N_{B e} / N_{H e}$, applying the least squares fit analysis described in the previous section. The results obtained from the TFTR experiments are shown in Figs 10 and 11. Due to the least squares fit analysis, it is possible to determine the relative charge state abundances very accurately with error bars. We note that the deduced abundance ratios are larger than the coronal equilibrium predictions. As shown in Figs 10 and 11 by data points for three different electron temperatures, a more involved analysis which includes chord-integrals assuming a coronal equilibrium distribution for the ion charge state distribution cannot explain the observed deviations. Based on the present coronal equilibrium calculations, particle diffusion coefficients, $D$, in the range from 1 to $2.5 \mathrm{~m}^{2} / \mathrm{s}$ are needed to explairs the TFTR results.

C

Intensity ratios of the heliumlike lines

The R-Ratio

$$
R(n e)=z /(x+y),
$$

and G-Ratio,

$$
G(T e)=(x+y+z) / w
$$

of the heliumlike lines $w, x, y$ and $z$ have important diagnostic applications for electron density measurements 28 in solar flares 29,30 and in laser-produced high-density plasmas, as well as for measurements of non-thermal electron energy distributions in tokamak plasmas with auxiliary RF heating. 31-33 However, with exception of the measurements of $\mathrm{SiXXIII}^{34}$ and $\mathrm{MgXI}^{35}$ from DITE, the data from tokamak experiments for the heliumlike line ratios are not in agreement with the theoretical predictions. $5,8,12,13,36$ As shown by the analysis of the two FeXXV spectra in section III, the ratios $x / w, y / w$ and $z / w$ are found to be larger (see Table III) than the predictions for direct electron impact excitation, which is the principal excitation mechanism. Additional processes, such as the excitation of the lines $w, x, y$, and $z$ by recombination of hydrogenlike ions and inner-shell ionization of lithiumlike ions, which contributes to the line $z$, cannot, in general, explain the observed ratios. In fact, the largest deviations occur for low electron temperai ires, 5,13 when the concentration of hydrogenlike ions is negligible. Similar deviations from the theoretical predictions have recently been found for the satellite spectrum of $\mathrm{CrXXIII}{ }^{37}$ from the Frascati 
Tokamak as shown in Fig. 12. The experimental data are compared with a synthetic spectrum (solid line) based on the theoretical predictions of J. Dubau for the dielectronic satellites and data of R. Mewe and J. Schrijver 38 for the relative intensities of the heliumlike lines $w, x, y$, and $z$. The electron and ion temperatures were $\mathrm{Te}=2.3 \mathrm{keV}$ and $\mathrm{Ti}=2.0 \mathrm{keV}$. The predictions 38 for the intensities of $w, x, y$, and $z$ are represented by the hatched areas. The synthetic spectrum also includes contributions to the line $z$ from the inner-shell ionization of lithiumlike ions, which were calculated for the density ratio $\mathrm{N}_{\mathrm{CrXXII}} / \mathrm{N}_{\mathrm{CrXXIII}}=0.45$ derived from the intensity ratio $\mathrm{q} / \mathrm{w}$. We point out that recent measurements of the TiXXI line ratios on EBIT were in good agreement with theory. ${ }^{39}$ Thus, the tokamak results for the heliumlike lines are still puzzling and need further investigation.

\section{X-ray spectroscopy on future large tokamaks}

In this section we discuss the potential diagnostic use of X-ray spectroscopy on future large tokamaks, such as ITER, the International Thermonuclear Experimental Reactor. The objectives of ITER are (1) to demonstrate controlled ignition and extended burn of D-T plasmas, (2) to validate the design concepts and engineering components for a fusion power reactor, and (3) to serve as a test facility for neutronics, blanket modules, tritium production and advanced technologies. 40 The conceptual design parameters of ITER are listed in Table IV. Comparing these parameters with those of present-day large tokamaks (see Table I), we note that crucial plasma parameters, such as the electron density and the ion temperature, $\mathrm{n}_{\mathrm{e}}=2 \times 10^{20} \mathrm{~m}^{-3}$ and $\mathrm{T}_{\mathrm{i}}=10$ $30 \mathrm{keV}$, are already obtained in the present experiments, but that other ITER parameters, such as the plasma volume $\left(500 \mathrm{~m}^{3}\right)$, the stored energy $(600 \mathrm{MJ})$, the energy yield from fusion products $(\sim 1 \mathrm{GW})$, the radiated power $(\sim 100 \mathrm{MW})$ and the pulse lengths $(>1000 \mathrm{sec})$, are by orders of magnitude larger than the parameters of the present tokamaks. A major problem for the operation of ITER will be the control of the plasma-wall interaction to maintain the required plasma purity of $Z_{\text {eff }}=1.7\left(Z_{\text {eff }}=1\right.$ corresponds to a pure deuterium-tritium plasma). The solution of this problem depends not only on a choice of appropriate wall and divertor materials, but also on the control of the energy release from the plasma. To control the energy release from the plasma and to reduce the heat load on the divertor under quasi-continuous operation with pulse lengths greater than 1000 $\mathrm{sec}$, it has recently been proposed 41 to inject high- $Z$ impurities into the plasma which can provide radiative cooling of the plasma edge region at a rate of $100 \mathrm{MW}$. Thus, contrary to present-day tokamaks, where every effort is made to reduce the level of plasma impurities, ITER may require the injection of impurities for its operation. The most likely candidate will be krypton $(Z=36)$, since it is chemically inert and since it can be easily introduced in controllable quantities. Krypton can solve two problems for ITER: (1) the radiation from the low krypton ion charge states can provide the required radiative cooling and (2) the charge state of heliumlike krypton, which will be the dominant state of ionization in the hot core of the plasma for the projected central electron temperatures of $30 \mathrm{keV}$, can be used for Doppler broadening measurements to determine the central 
ion temperature $T_{i}(0)$. We point out that ion temperature measurements by the techniques of charge exchange recombination spectroscopy, which are now widely used on tokamaks and which require the injection of neutral hydrogen beams, may not be applicable since neutral deuterium beams will not penetrate to the core of the plasma. However, the development of efficient high-resolution crystal spectrometers for Doppler broadening measurements at wavelengths of $0.95 \AA$ will be an experimental challenge. Futhermore, it is important to establish a reliable atomic physics data base on high-Z elements, such as krypton, in order to predict by plasma simulation calculations the effects of radiative cooling for the different experimental conditions on ITER. The atomic data base for the ITER experiment must include other elements, which may be constituents of the plasma facing components like carbon, iron, nickel, molybdenum, tungsten, beryllium, and boron or contaminants like oxygen. Especially important are data on rate coefficients for ionization, recombination and line excitation for all the ion charge states of these elements. Obviously, atomic physics contributions are essential to solve the many critical problems related to the control of the energy release from the plasma, the diagnostics of plasma parameters, issues of the plasma-wall interaction and the removal of the 'helium ash' due to DT fusion reactions from the plasma. Experiments are now under way, on TFTR and EBIT, to study the spectra of the different krypton ion charge states and to investigate the effects of krypton on the plasma performance.

\section{Conclusion}

High-resolution crystal spectrometers have been very important for the X-ray diagnostics of central plasma parameters in present tokamak fusion experiments. In particular, the Doppler broadening and Doppler shift measurements of the $1 \mathrm{~s}-2 \mathrm{p}$ resonance lines of iigh- $Z$ heliumlike ions have been invaluable for the determination of the central ion temperature and the central plasma motion in tokamak experiments with auxiliary heating by neutral beam injection and ion cyclotron heating. In fact, these measurements were essential for the discovery and characterization of new tokamak operating regimes with enhanced particle and energy confinement. Since tokamak plasmas are well-diagnosed by independent measurements of the electron temperature and the electron density, high-resolution spectra of heliumlike ions obtained from these plasmas are well suited for a detailed comparison with atomic theories. It is found that the spectra of dielectronic and 'collisional' satellites which are associated with the heliumlike resonance lines are accurately described by only four parameters, $T_{i}, T_{e}, N_{L i} / N_{H e}$ and $N_{B e} / N_{H e}$, in excellent agreement with the theoretical predictions. The intensity ratios of the dielectronic satellites and the heliumlike resonance line can therefore be used for electron temperature measurements and measurements of the dielectronic recombination rate coefficients of heliumlike ions. The relative ion charge-state abundances, $\mathrm{N}_{\mathrm{Li}} / \mathrm{N}_{\mathrm{He}}$ and $\mathrm{N}_{\mathrm{Be}} / \mathrm{N}_{\mathrm{He}}$, which are obtained from the intensity ratios of the 'collisional' satellites and the resonance line, are larger than the predictions for coronal equilibrium. The observed deviations can be ascribed to effects of radial ion transport in tokamak plasmas; however, uncertainties in the theoretical data for ionization and recombination rate coefficients, 
which are used for the coronal equilibrium calculations, are still a concern for a quantitative determination of the transport coefficients. The ratios of the heliumlike lines $x / w, y / w$ and $z / w$ are larger than predicted by the processes of direct excitation, recombination of hydrogenlike ions, and inner-shell ionization of lithiumlike ions. Heliumlike ions of elements with still higher Z, like krypton, will be important for the diagnostic of the central plasma parameters in future large tokamaks, such as ITER. The development of efficient high-resolution crystal spectrometers for Doppler broadening measurements at wavelengths $\lambda \leq 1 \AA$ will be an experimental challenge.

Acknowledgements. We gratefully acknowledge fruitful discussions with R. Barnsley, F. Bombarda and P. Platz, who also provided us with spectral data from the DITE, the FTU and the TFR tokamak experiments. We thank $S$. Cohen for valuable information on the ITER related physics issues. We also gratefully acknowledge the continuing support of R. J. Hawryluk, and K. M. Young as well as the technical assistance of J. Gorman, R. Such and the TFTR operating crew. This work was supported by the U.S. Department of Energy, Contract No. DE-AC02-76-CHO-3073. 
Table I: Parameters of the Tokamak Fusion Test Reactor (TFTR) Experiments

Plasma Major Radius, $\mathbf{R}$

Plasma Minor Radius, a

Toroidal Magnetic Field, $\mathbf{B}_{\mathbf{T}}$

Plasma Current, I

Auxiliary Heating:

Neutral Beam Heating, NBI

Ion Cyclotron Heating, ICH

Electron Density, $\mathbf{n}_{\mathbf{e}}$

Electron Temperature, $\mathbf{T}_{\mathbf{e}}$

Ion Temperature, $\mathbf{T}_{\mathbf{i}}$

Stored Energy, E

D-D neutron yields

Pulse Length

n $\tau \mathrm{T}_{\mathbf{i}}\left(10^{20} \mathrm{~m}^{-3} \mathrm{sec} \mathrm{keV}\right)$
$2.65 \mathrm{~m}$

$0.95 \mathrm{~m}$

5.0 Tesla

0.6-3.0 MA

$35 \mathrm{MW}$

$12 \mathrm{MW}$

$0.1-3 \times 10^{20} \mathrm{~m}^{-3}$

$1-10 \mathrm{keV}$

1-35 keV

1-5 MJ

$\leq 6 \times 10^{16} \mathrm{sec}^{-1}$

$6 \mathrm{sec}$

4.3 
TABLE II: Theoretical wavelengths for the heliumlike transitions $w, x, y$ and $z$ of FeXXV and the associated main $n=2$ satellites. Also listed are the satellite line strengths, $F_{2}(s)$.

\begin{tabular}{|c|c|c|c|}
\hline Key & Transition & $\begin{array}{c}\text { Wavelength } \\
(\AA ̊)\end{array}$ & $\begin{array}{c}F_{2}(s) \\
\left(10^{13} s^{-1}\right)\end{array}$ \\
\hline $\mathbf{w}$ & $1 s^{2}{ }_{S_{0}}-1 s 2 p{ }^{1} P_{1}$ & 1.8498 & - \\
\hline $\mathbf{x}$ & $1 s^{2}{ }^{1} S_{0}-1 s 2 p{ }^{3} P_{2}$ & 1.85503 & - \\
\hline $\mathrm{t}$ & $1 s^{2} 2 s^{2} s_{1 / 2}-1 s 2 p 2 s\left({ }^{3} p\right)^{2} P_{1 / 2}$ & 1.8566 & 10.9 \\
\hline $\mathbf{y}$ & $1 s^{2}{ }^{1} S_{0}-1 s 2 p P_{1}$ & 1.8590 & - \\
\hline$q$ & $1 s^{2} 2 s^{2} s_{1 / 2}-1 s 2 p 2 s\left({ }^{1} P\right)^{2} P_{3 / 2}$ & 1.8605 & 0.003 \\
\hline k & $1 s^{2} 2 p^{2} P_{1 / 2}-1 s^{2} p^{2} 2 D_{3 / 2}$ & 1.8626 & 35.0 \\
\hline $\mathbf{r}$ & $1 s^{2} 2 s^{2} s_{1 / 2}-1 s 2 p 2 s\left({ }^{1} P\right)^{2} P_{1 / 2}$ & 1.8631 & 6.73 \\
\hline j & $1 s^{2} 2 p^{2} P_{3 / 2}-1 s 2 p^{2}{ }^{2} D_{5 / 2}$ & 1.8654 & 51.3 \\
\hline $\mathbf{z}$ & $1 s^{2}{ }^{1} S_{0}-1 s 2 s S^{3}$ & 1.8676 & - \\
\hline$\beta$ & $1 s^{2} 2 s^{2} 1 S_{0}-1 s 2 p 2 s^{2}{ }^{1} P_{1}$ & 1.87003 & 0.86 \\
\hline
\end{tabular}


Table III: Parameter values obtained from least squares fits of synthetic spectra to the observed spectra shown in Figs. 6 and 7, for the case with ohmic heating (Column $\mathbf{A}$ ) and the case with additional neutral beam heating (Column B).

\begin{tabular}{lll}
\hline Parameters & A & B \\
\hline $\mathrm{T}_{\mathrm{i}}(\mathrm{keV})$ & $3.2 \pm 0.1$ & $20.7 \pm 0.3$ \\
$\mathrm{~T}_{\mathrm{e}}(\mathrm{keV})$ & $3.29 \pm 0.04$ & $8.2 \pm 0.4$ \\
$\mathrm{nLi}_{\mathrm{i}} / \mathrm{n} \mathrm{He}$ & $0.376 \pm 0.012$ & $0.260 \pm 0.008$ \\
$\mathrm{n}_{\mathrm{Be}} / \mathrm{n} H \mathrm{He}$ & $0.144 \pm 0.013$ & $0.018 \pm 0.005$ \\
$\mathrm{xa}$ & $1.59 \pm 0.05$ & $2.49 \pm 0.08$ \\
$\mathrm{ya}$ & $1.61 \pm 0.04$ & $1.80 \pm 0.04$ \\
$\mathrm{za}$ & $1.65 \pm 0.04$ & $2.29 \pm 0.06$ \\
\hline
\end{tabular}


Table IV: Conceptual Design Parameters of the International Thermonuclear Experimental Reactor (ITER)

Plasma Major Radius, $\mathbf{R}$

Plasma Minor Radius, a

Toroidal Magnetic Field, $\mathbf{B}$ T

Plasma Current, I $\mathbf{p}$

Auxiliary Heating:

Electron Density, $\mathbf{n}_{\mathbf{e}}$

$\mathrm{Z}_{\text {eff }}$

Electron Temperature, $\mathbf{T}_{\boldsymbol{2}}$

Ion Temperature, $\mathbf{T}_{\mathbf{i}}$

Stored Thermal Energy, E

Fusion Products, Pfusion

Alpha Particles, $\mathbf{P}_{\mathbf{a}}$

Radiated Power, $P_{\text {rad }}$

Pulse Length

n $\tau \mathbf{T}_{\mathbf{i}}\left(10^{21} \mathrm{~m}^{-3} \mathrm{sec} \mathrm{keV}\right)$
$6.0 \mathrm{~m}$

$2.15 \mathrm{~m}$

4.85 Tesla

$22 \mathrm{MA}$

$115 \mathrm{MW}$

$2 \times 10^{20} \mathrm{~m}^{-3}$

1.7

$10-30 \mathrm{keV}$

$10-30 \mathrm{keV}$

$600 \mathrm{MJ}$

$1000 \mathrm{MW}$

$200 \mathrm{MW}$

$100 \mathrm{MW}$

$400-2500 \mathrm{sec}$

$4-8$ 


\section{Figure Captions}

Figure 1: Schematic of the Tokamak Fusion Test Reactor (TFTR) showing one half of a vertical cross-section. The dotted lines represent the vertical axis of the torus and the horizontal midplane. Also shown is the arangement of the TFTR Horizontal and Vertical X-ray Crystal Spectrometers for Doppler broadening measurements of the ion temperature.

Figure 2: Satellite spectra of heliumlike ions from Reference 22.

Figure 3: Fractional abundances of iron ion charge states as a function of the electron temperature for coronal equilibrium conditions after Reference 23.

Figure 4: Ion temperature results from Doppler broadening measurements of the FeXXV 1s-2p resonance line $w$. The data were recorded from a TFTR deuterium plasma with $20 \mathrm{MW}$ of auxiliary heating by deuterium neutral beam injection (NBI) from 3 to $4 \mathrm{sec}$ using the TFTR Horizontal Crystal Spectrometer.

Figure 5: Time evolutions of the electron temperature and electron density from the same discharge as in Fig. 4.

Figure 6: Satellite spectrum of FeXXV. The experimental data (circles) were recorded from the same discharge as in Fig. 4 during the period of ohmical heating from 2.5 to 3 sec. Also shown is a synthetic spectrum with its various spectral components (solid lines) which was constructed from a least squares fit of theoretical predictions of References 15 and 18 to the experimental data.

Figure 7: Satellite spectrum of FeXXV recorded from the same discharge as in Fig. 4 during the period of neutral beam injection from 3.5 to $4 \mathrm{sec}$. The synthetic spectrum was constructed as described in caption of Fig. 6.

Figure 8: Electron temperature profile measured by the laser Thomson scattering diagnostic at 3.5 sec from the same discharge as in Fig. 4.

Figure 9: Dielectronic recombination rate coefficient of FeXXV as a function of the elctron temperature from Reference 26.

Figure 10: Comparison of the relative abundances of lithiumlike and heliumlike nickel with coronal equilibrium predictions from Reference 13. 
Figure 11: Comparison of the relative abundances of berylliumlike and heliumlike nickel with coronal equilibrium predictions from Reference 13.

Figure 12: Satellite spectrum of CrXXIII from the Frascati tokamak experiment. The solid lines represent theoretical predictions from References 6 and 38. 


\section{References}

(1) E. Källne, J. Källne, A. Dalgarno, E. S. Marmar, J. E. Rice, and A. Pradhan, Phys. Rev. Lett. 52, 2245 (1984)

(2) TFR Group, F. Bombarda, F. Bely-Dubau, P. Faucher, M. Cornille, J. Dubau, and M. Loulergue, Phys. Rev. A 32, 2374 (1985)

(3) F. Bely-Dubau, P. Faucher, L. Steenman-Clark, M. Bitter, S. von Goeler, K. W. Hill, C. Camhy-Val, and J. Dubau, Phys. Rev. A 26,3459 (1982)

(4) P. Lee, A. J. Lieber, and S. S. Wojtowicz, Phys. Rev. A 31, 3996 (1985)

(5) M. Bitter, K. W. Hill, M. Zarnstorff, S. von Goeler, R. Hulse, L. C. Johnson, N. R. Sauthoff, S. Sesnic, K. M. Young, M. Tavernier, F. Bely-Dubau, P. Faucher, M. Cornille, and J. Dubau, Phys. Rev. A 32, 3011 (1985)

(6) TFR group, J. Dubau, and M. Loulergue, J. Phys. B 15, 1007 (1981)

(7) M. L. Apicella, R. Bartiromo, F. Bombarda, and R. Giannella, Phys. Let 98A, 174 (1983)

(8) M. Bitter, K. W. Hill, N. R. Sauthoff, P. C. Efthimion, E. Meservey, W. Roney, S. von Goeler, R. Horton, and W. Stodiek, Phys. Rev. Lett. 43, 129 (1979)

(9) M. Bitter, S. von Goeler, K. W. Hill, R. Horton, D. Johnson, W. Roney, N. R. Sauthoff, E. Silver and W. Stodiek, Phys. Rev. Lett. 47, 921 (1981)

(10) H. Hsuan, M. Bitter, K. W. Hill, S. von Goeler, B. Grek, D. Johnson, L. C. Johnson, S. Sesnic, C. P. Bhalla, K. R. Karim, F. Bely-Dubau, and P. Faucher, Phys. Rev. A 35 , 4280 (1987)

(11) F. Bombarda, R. Giannella, E. Källne, G. J. Tallents, F. Bely-Dubau, P. Faucher, M. Cornille, J. Dubau, and A. H. Gabriel, Phys. Rev. A 37, 504 (1988)

(12) K.-D. Zastrow, E. Källne, and H. P. Summers, Phys. Rev. A 41, 1427 (1990)

(13) M. Bitter, H. Hsuan, V. Decaux, B. Grek, K. W. Hill, R. Hulse, L. A. Kruegel, D. Johnson, S. von Goeler, and M. Zarnstorff, Phys. Rev. A 44, 1796 (1991) 
(14) A. H. Gabriel, Mon. Not. R. Astron. Soc. 160, 99 (1972)

(15) F. Bely-Dubau, J. Dubau, P. Faucher, A. H. Gabriel, Mon. Not. R. Astron. Soc., 198, 239 (1982)

(16) L. A. Vainshtein and U. I. Safronova, At. Data Nucl. Data Tables 21,49 (1978)

(17) L. A. Vainshtein and U. I. Safronova, At. Data Nucl. Data Tables 25,311 (1980)

(18) U.I. Safronova, A. M. Urnov and L. A. Vainshtein, Proc. P. N. Lebedev Phys. Inst. [Acad. Sci. USSR] 119, 13 (1980).

(19) L. A. Vainshtein and U.I. Safronova, P. N. Lebedev Physical Institute, Moscow, and Institute of Spectroscopy, Troizk, USSR Academy of Science, Moscow, USSR, Rep. 3 (1985)

(20) H. Hsuan, M. Bitter, J. E. Rice, K. W. Hill, L. Johnson, S. L. Liew, S. D. Scott and S. von Goeler, Rev. Sci. Instrum. 59, 2127 (1988)

(21) M. Bitter, H. Hsuan, J. E. Rice, K. W. Hill, M. Diesso, B. Grek, R. Hulse, D. W. Johnson, L. C.and S. von Goeler, Rev. Sci. Instrum. 59, 2131 (1988)

(22) TFR group, M. Comille, J. Dubau, and M. Loulergue, Phys. Rev. A 32, 3000 (1985)

(23) C. Breton, C. De Michelis, M. Finkenthal, and M. Matioli, Fontenay-aux-Roses Laboratory Report No. EUR-CEA-FC-948, 1978 (unpublished)

(24) D. A. Knapp, R. E. Marrs, M. A. Levine, C. L. Bennett, M. H. Chen, J. R. Henderson, M. B. Schneider, and J. H. Scofield, Phys. Rev. Lett. 62, 2104 (1989)

(25) F. Bely-Dubau., A. H. Gabriel, and S. Volonté, Mon. Not. R. Astron. Soc. 186, 405 (1979)

(26) F. Bely-Dubau., M. Bitter, J. Dubau, P. Faucher, A. H. Gabriel,K. W. Hill, S. von Goeler, N. Sautjhoff, and S. Volonté, Phys. Lett. 93A, 189 (1983)

(27) M. Bitter, H. Hsuan, S. von Goeler K. W. Hill, B. Grek, and D. W. Johnson, Physica Scripta T37, 66 (1991) 
(28) R. W. P. McWhirter in Coursc on Plasma Diagnostics and Data Acquisition Systems, Varenna - Villa Monastero - Italy, September 3-11, 1975, edited by H. Eubank and E. Sindoni (Editrice Compositori - Bologna, 1975)

(29) G. A. Linford and C. J. Wolfson, Astrophys. J. 331, 1036 (1988)

(30) D. L. McKenzie, Astrophys. J. 322, 512 (1987)

(31) P. Lee, A. J. Lieber, R. P. Chase, and A. K. Pradhan, Phys. Rev. Let. 55, 386 (1985)

(32) P. Lee, A. J. Lieber, A. K. Pradhan, and Yueming Xu, Phys. Rev. A 34, 3210 (1986)

(33) R. Bartiromo, F. Bombarda and R. Giannella, Phys. Rev. A 32, 531 (1985)

(34) F. P. Keenan, S. M. McCann, R. Barnsley, J. Dunn, K. D. Evans, and N. J. Peacock, Phys. Rev. A 39, 4092 (1989)

(35) F. P. Keenan, S. M. McCann, A. E. Kingston, R. Bamsley, J. Dunn, and N. J. Peacock, Phys. Rev. A 44, 3831 (1991)

(36) Takako Kato, Shigeru Morita and Kuniaki Masai, Phys. Rev. A. 36,795 (1987)

(37) F. Bombarda, private communication

(38) R. Mewe and J. Schrijver, Astr. Ap. 87, 55 (MSc) (1980)

(39) S. Chantrenne, P. Beiersdorfer; R. Cauble, and M. B. Schneider, Phys. Rev. Lett. 69, 265 (1992)

(40) ITER Documentation Series, No. 23, ITER Operations and Research Programme, International Atomic Energy Agency, Vienna, 1991

(41) C. J. Cummings, S. A. Cohen, R. Hulse, D. E. Post, and M. Redi, Journal of Nuclear Materials 176\&177, $916(1990)$ 


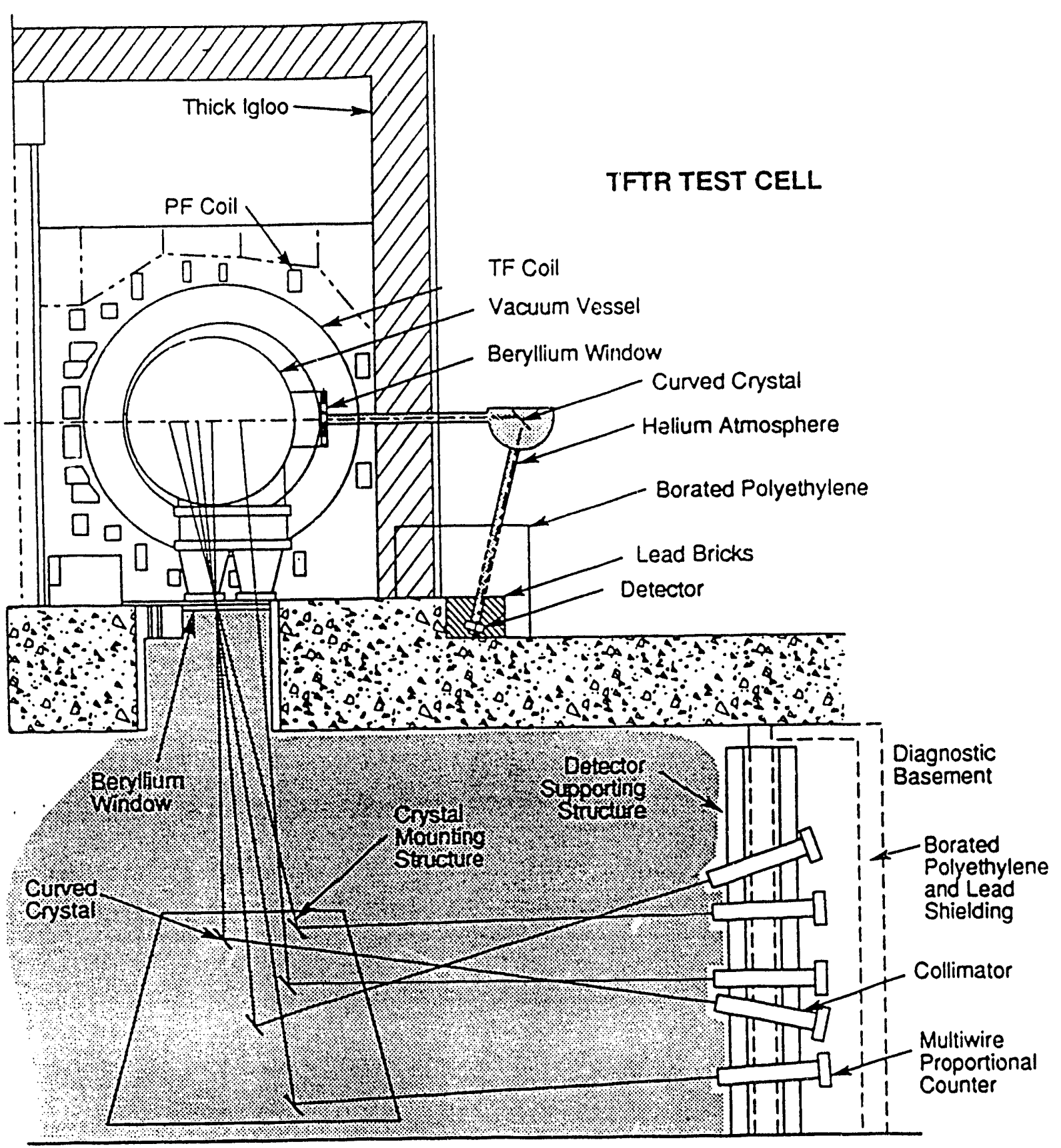

Fig. 1 

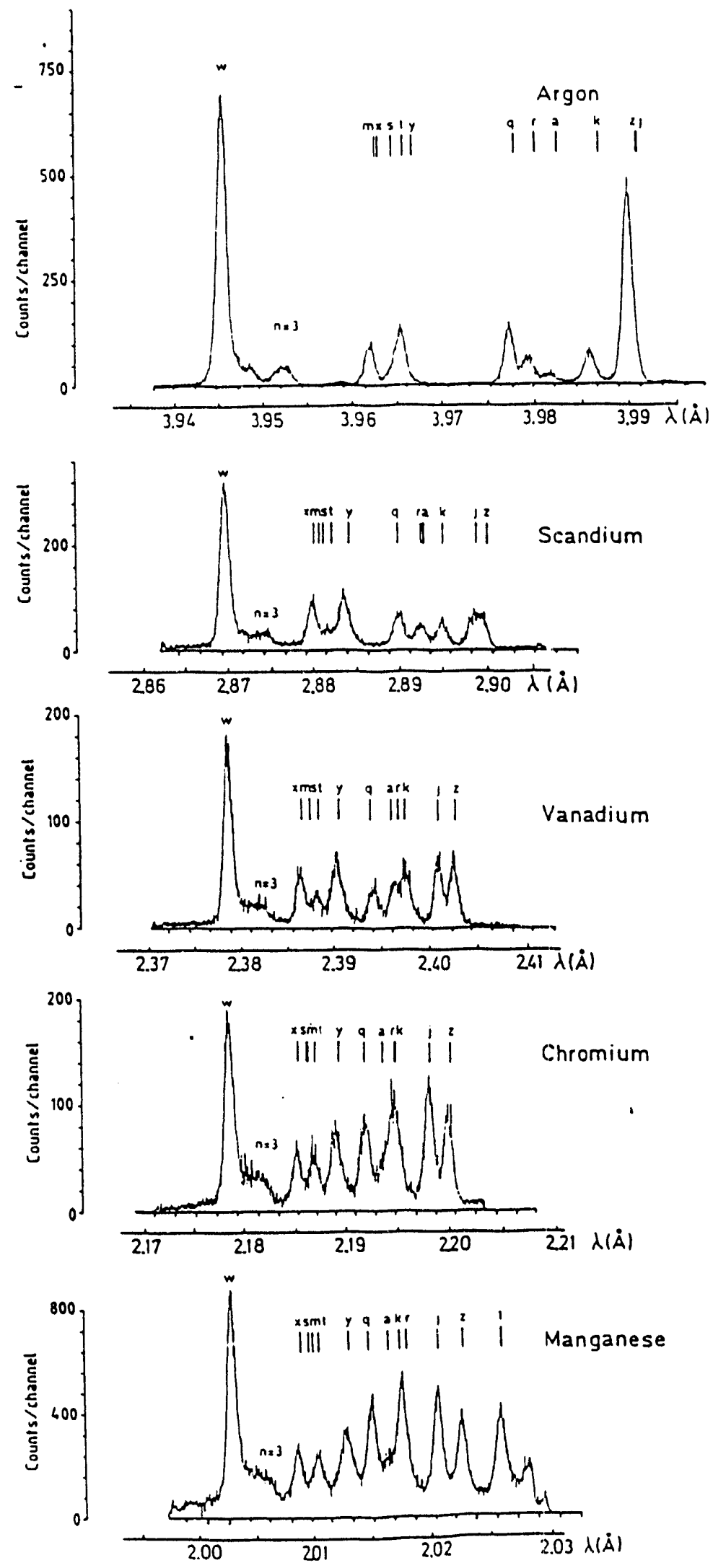

Fig. 2 


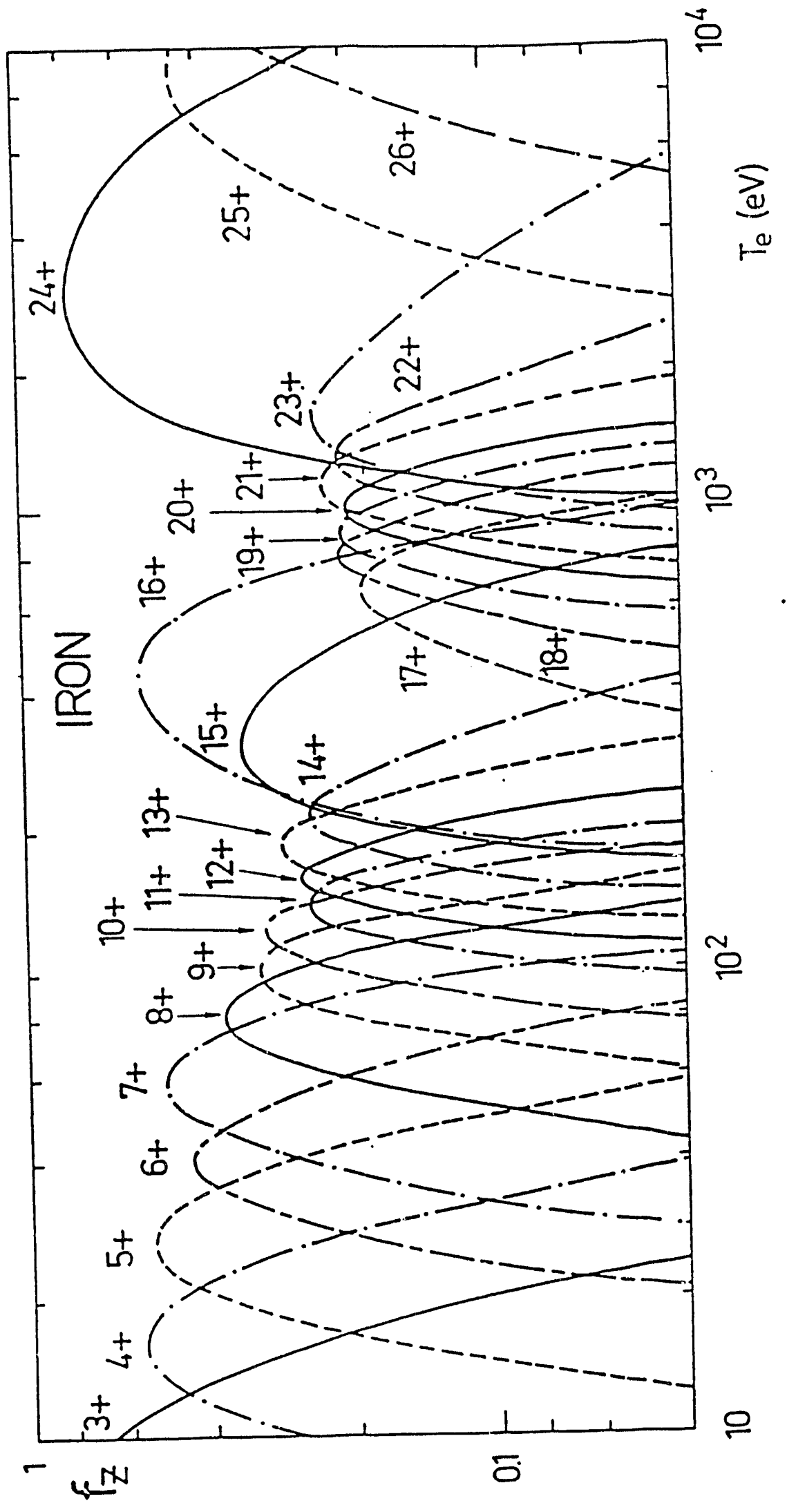

$\underset{m}{m}$ 


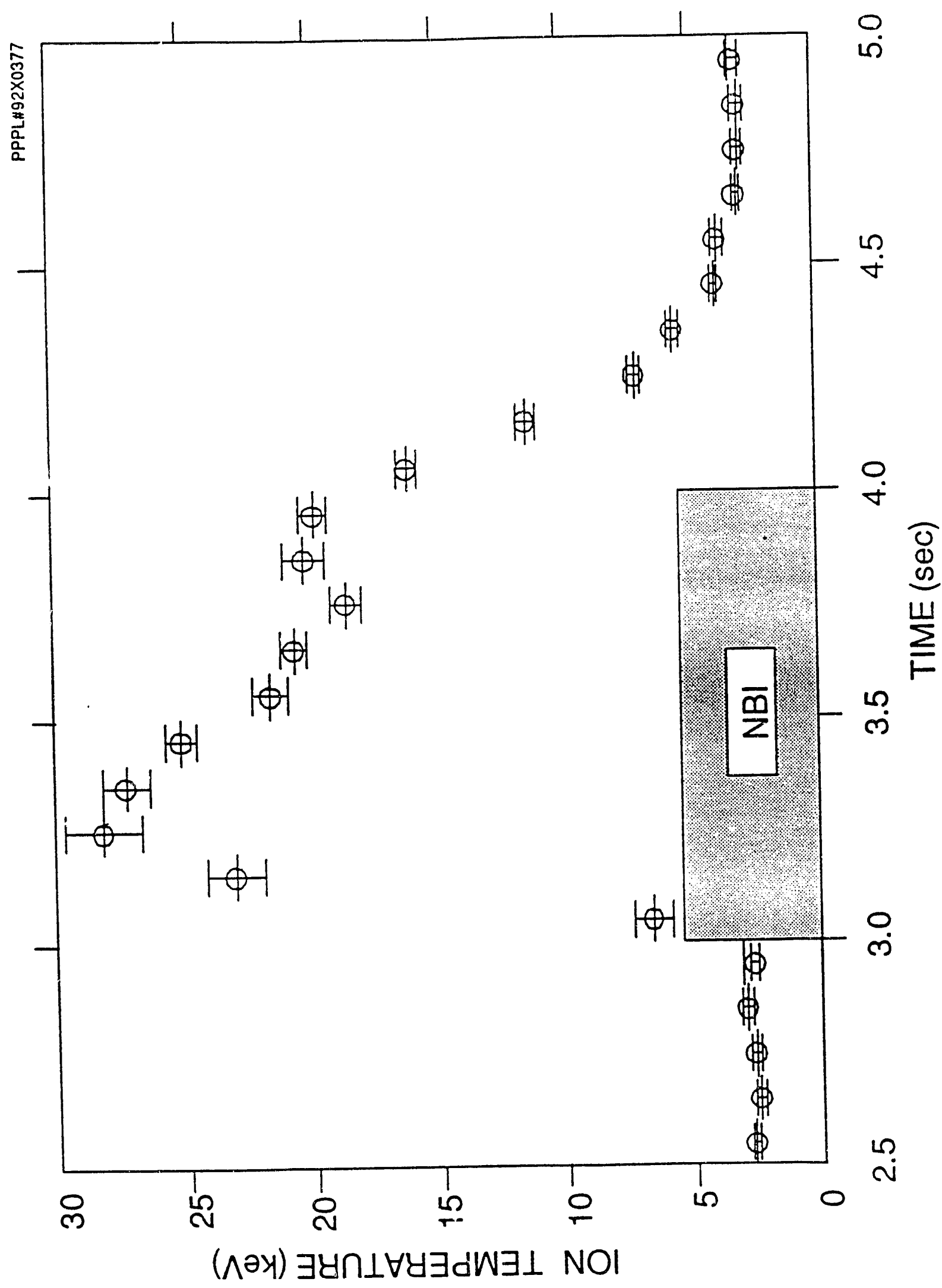



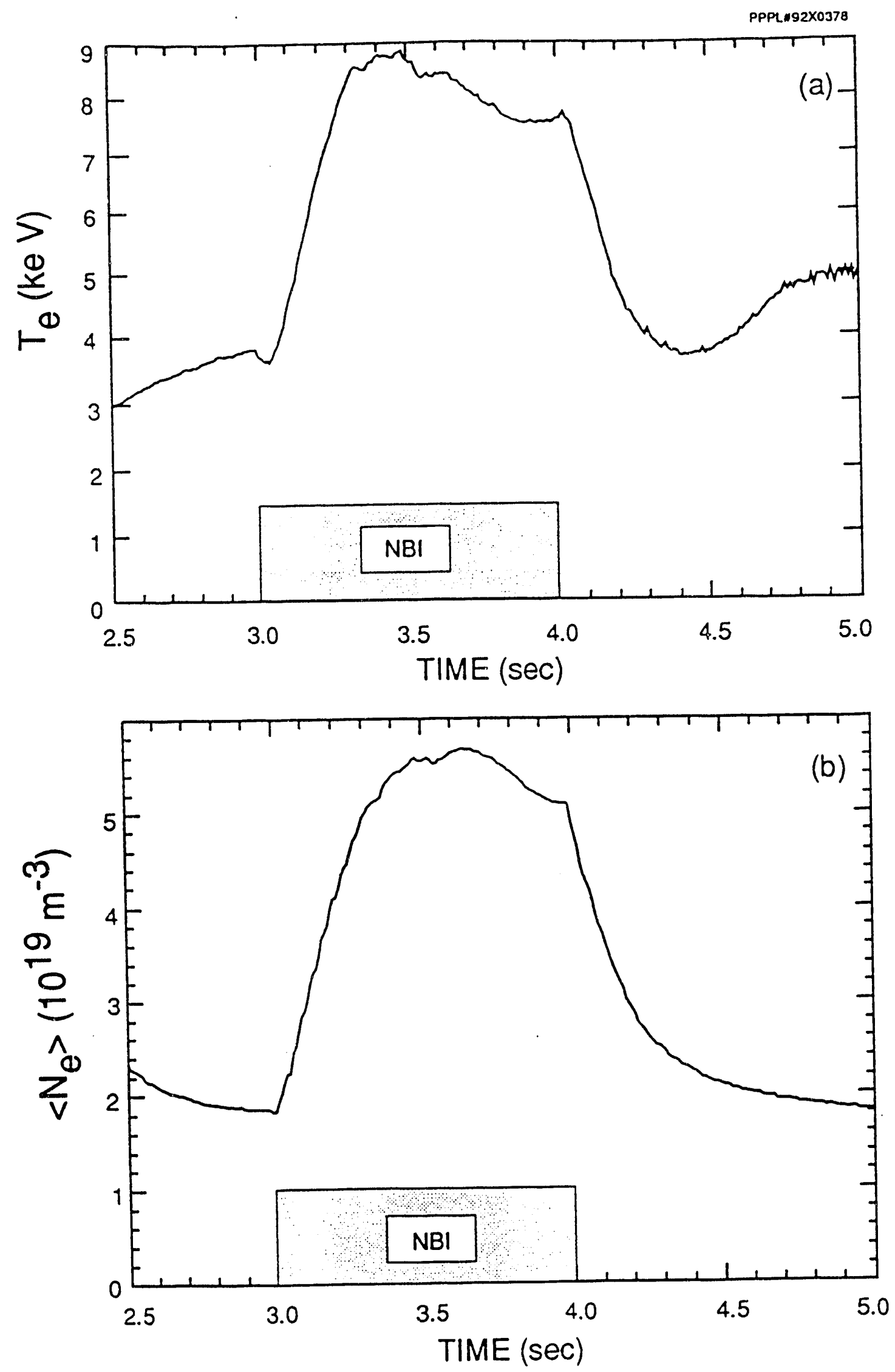

Fig. 5 


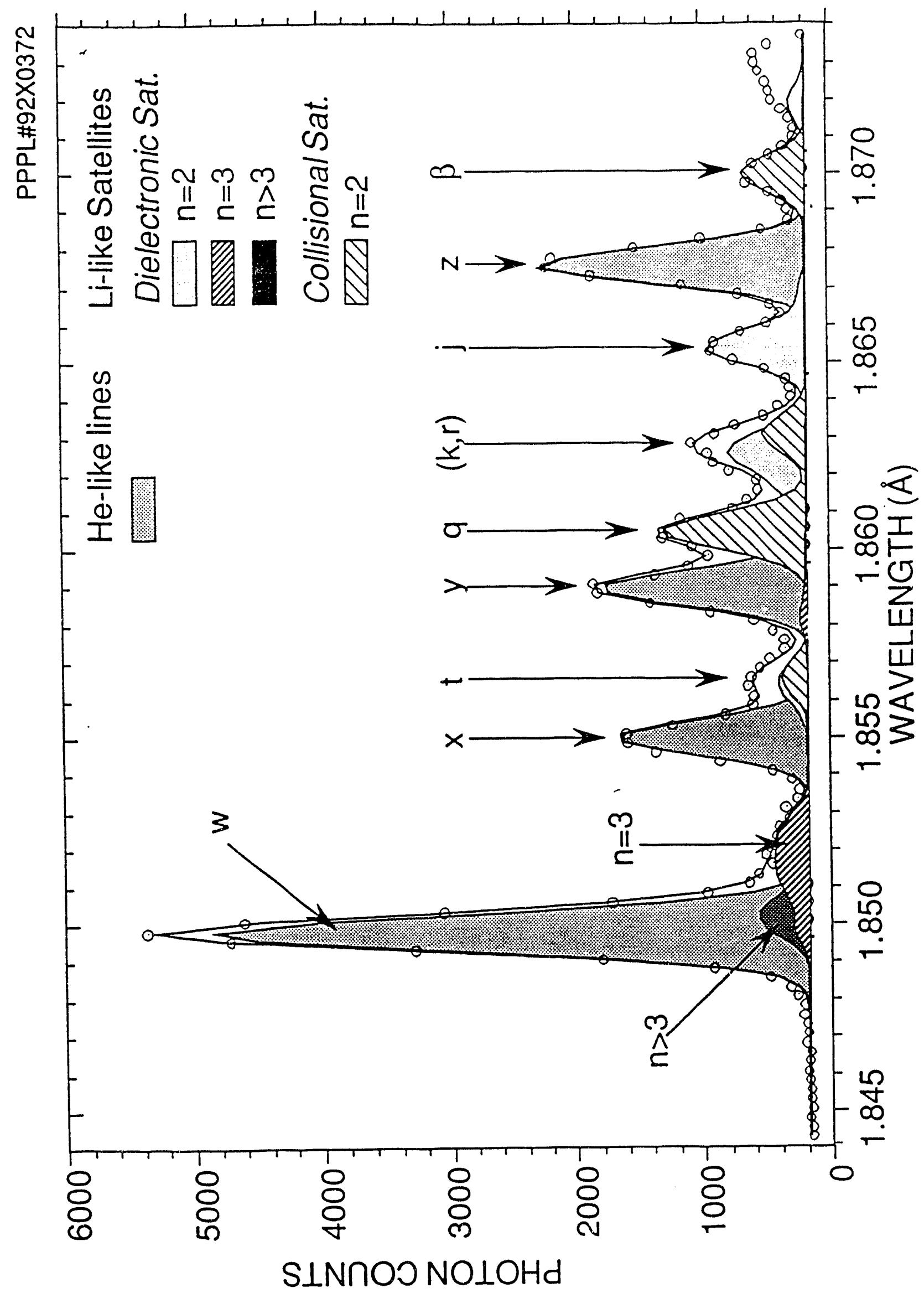




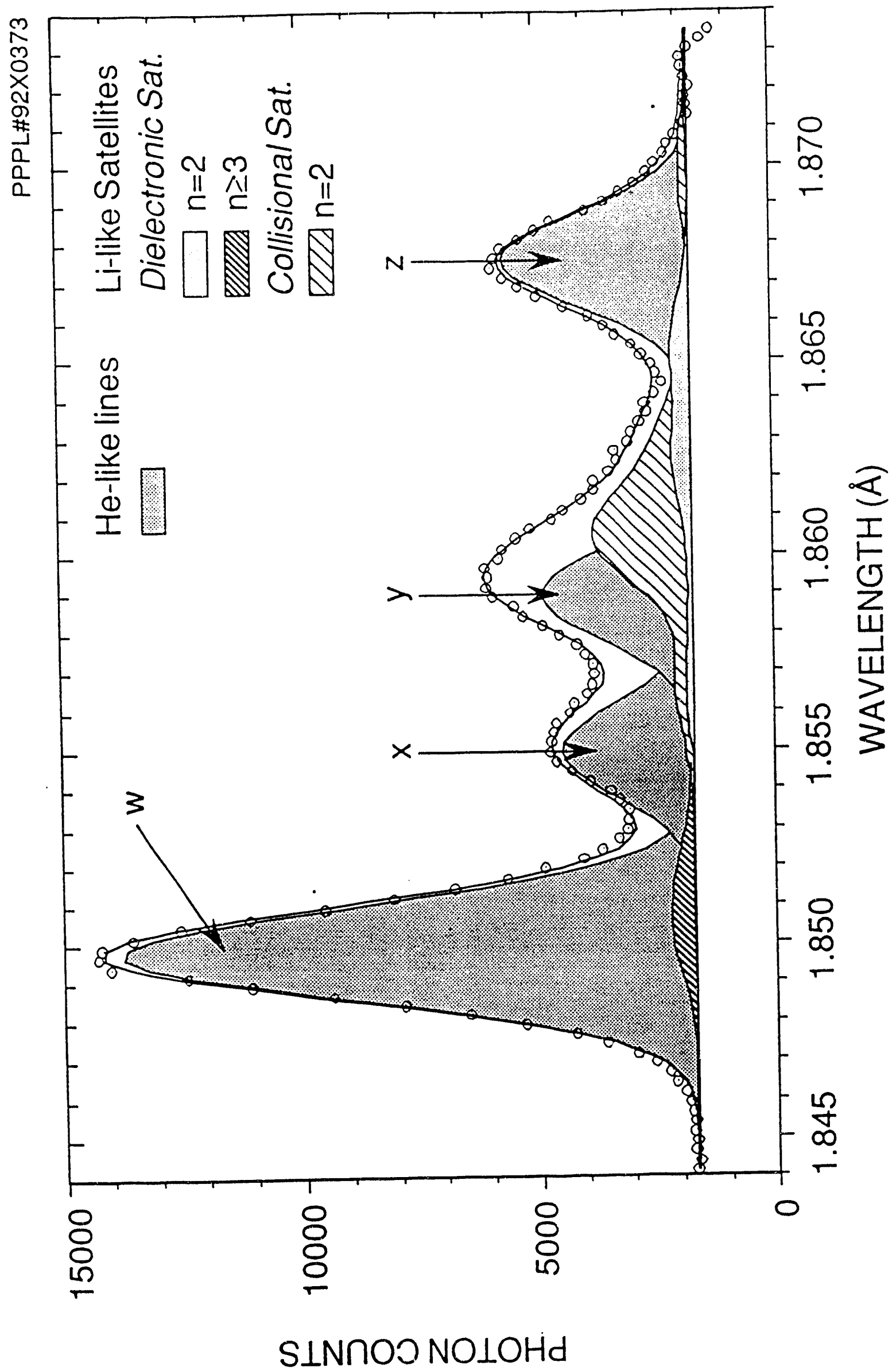




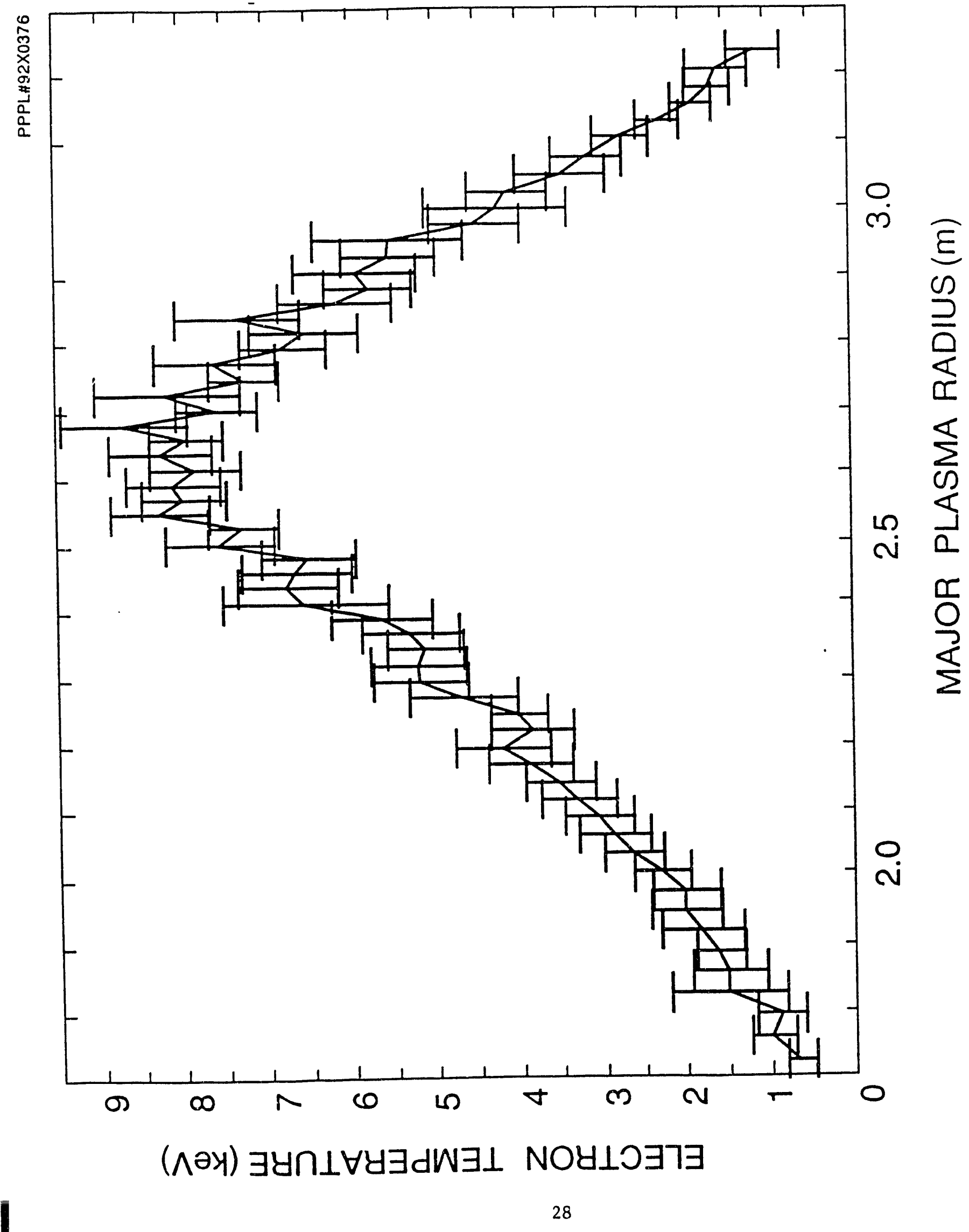


\# $82 \times 1112$

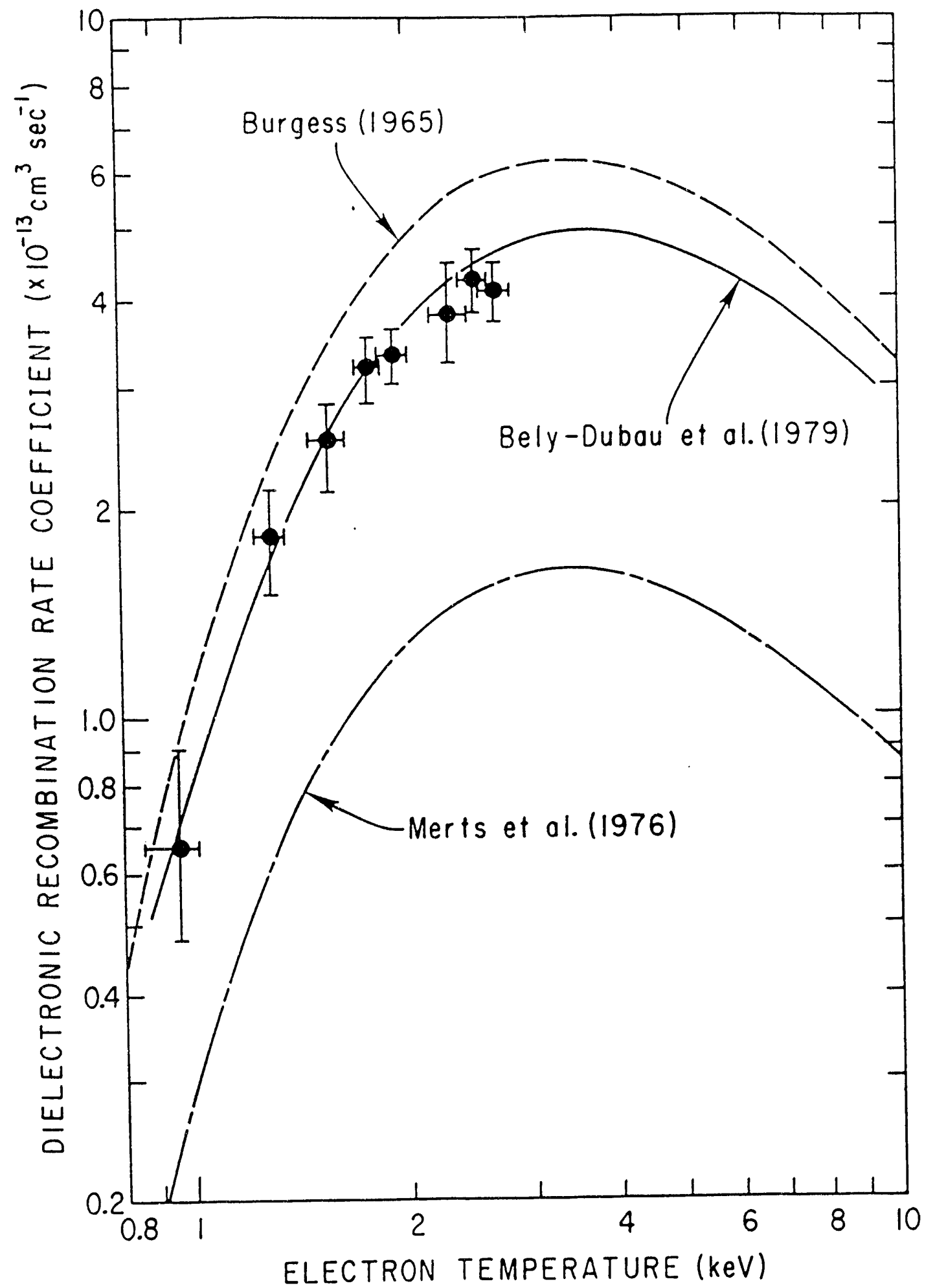

Fig. 9 


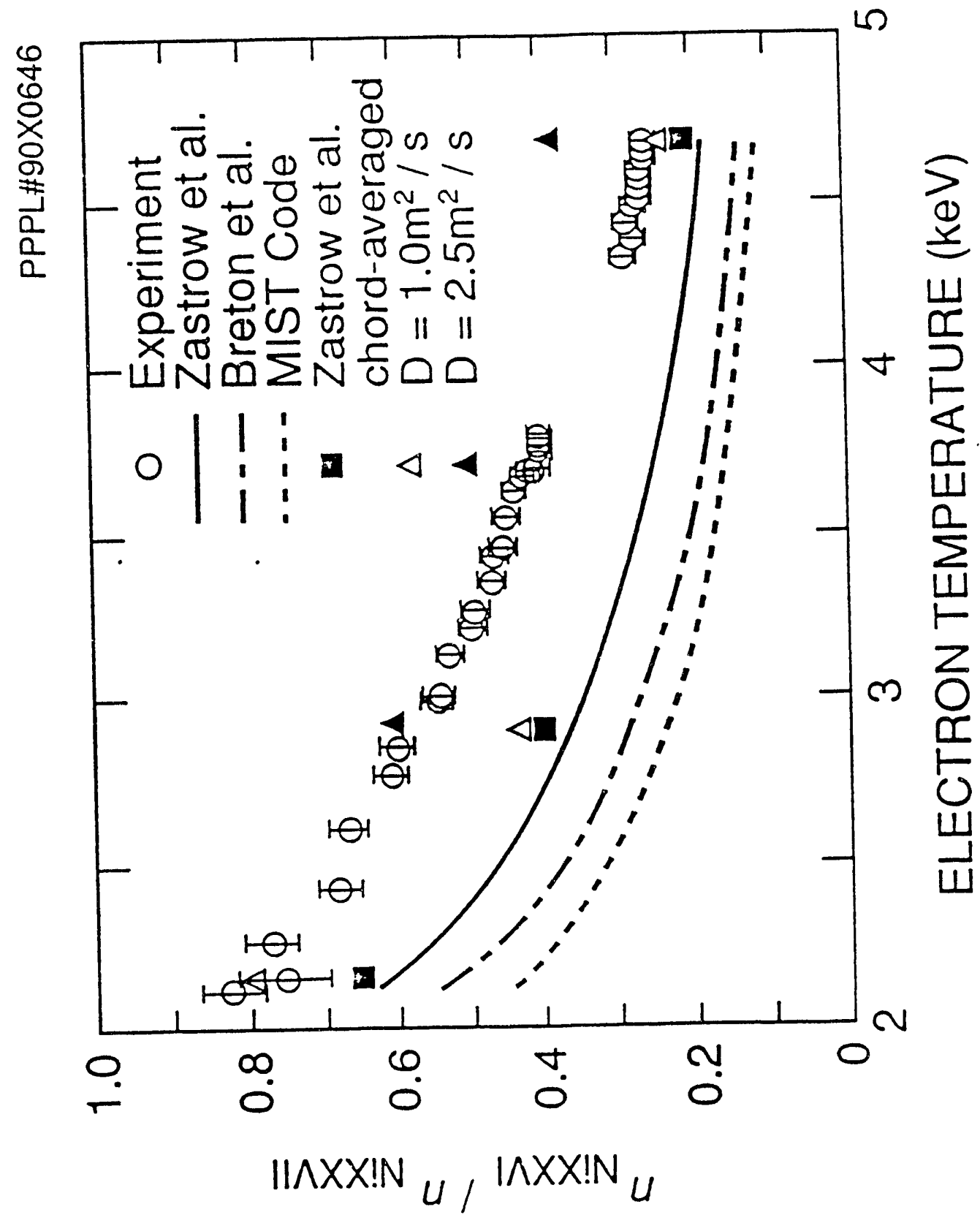

0
$\therefore$
$\therefore$ 


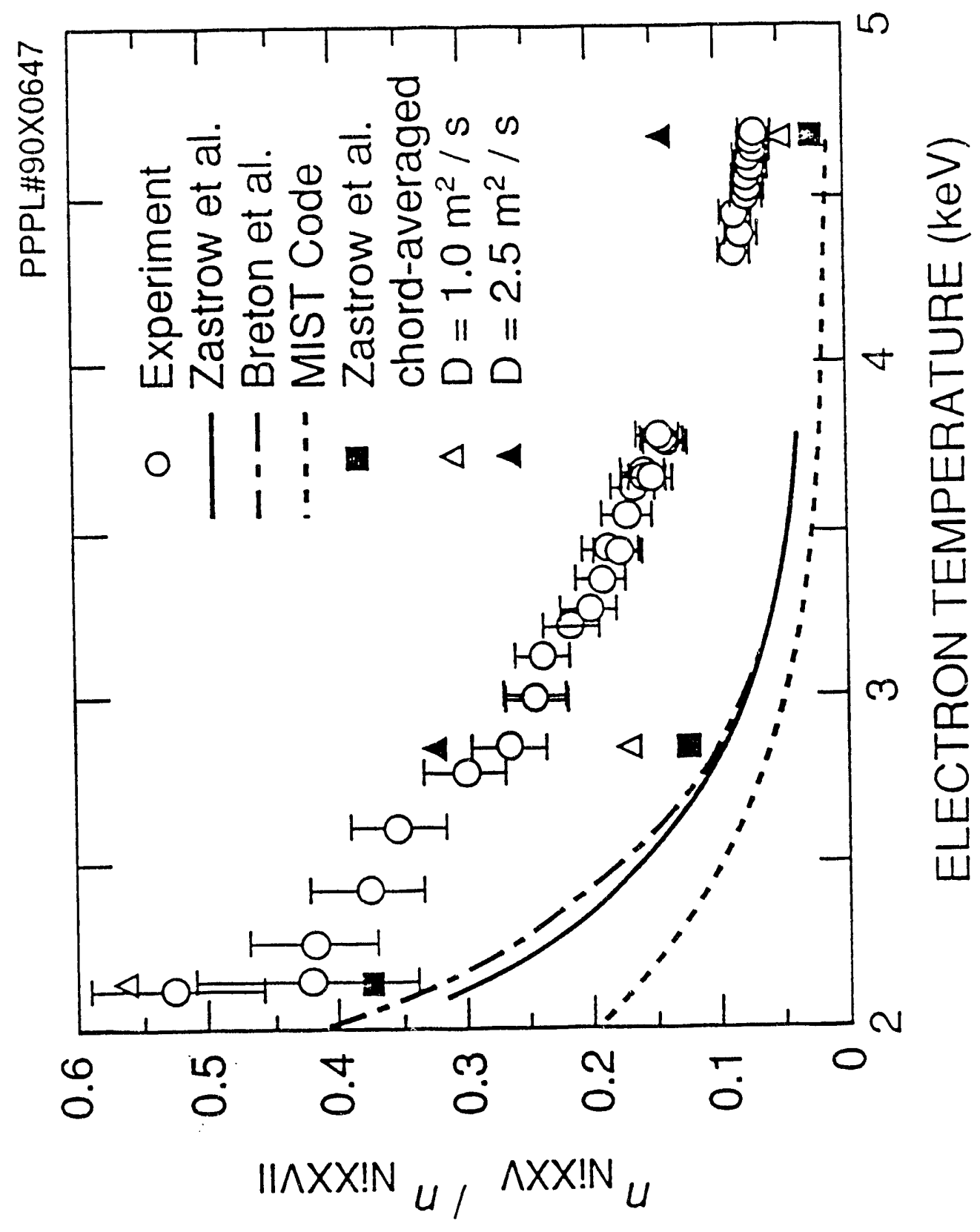




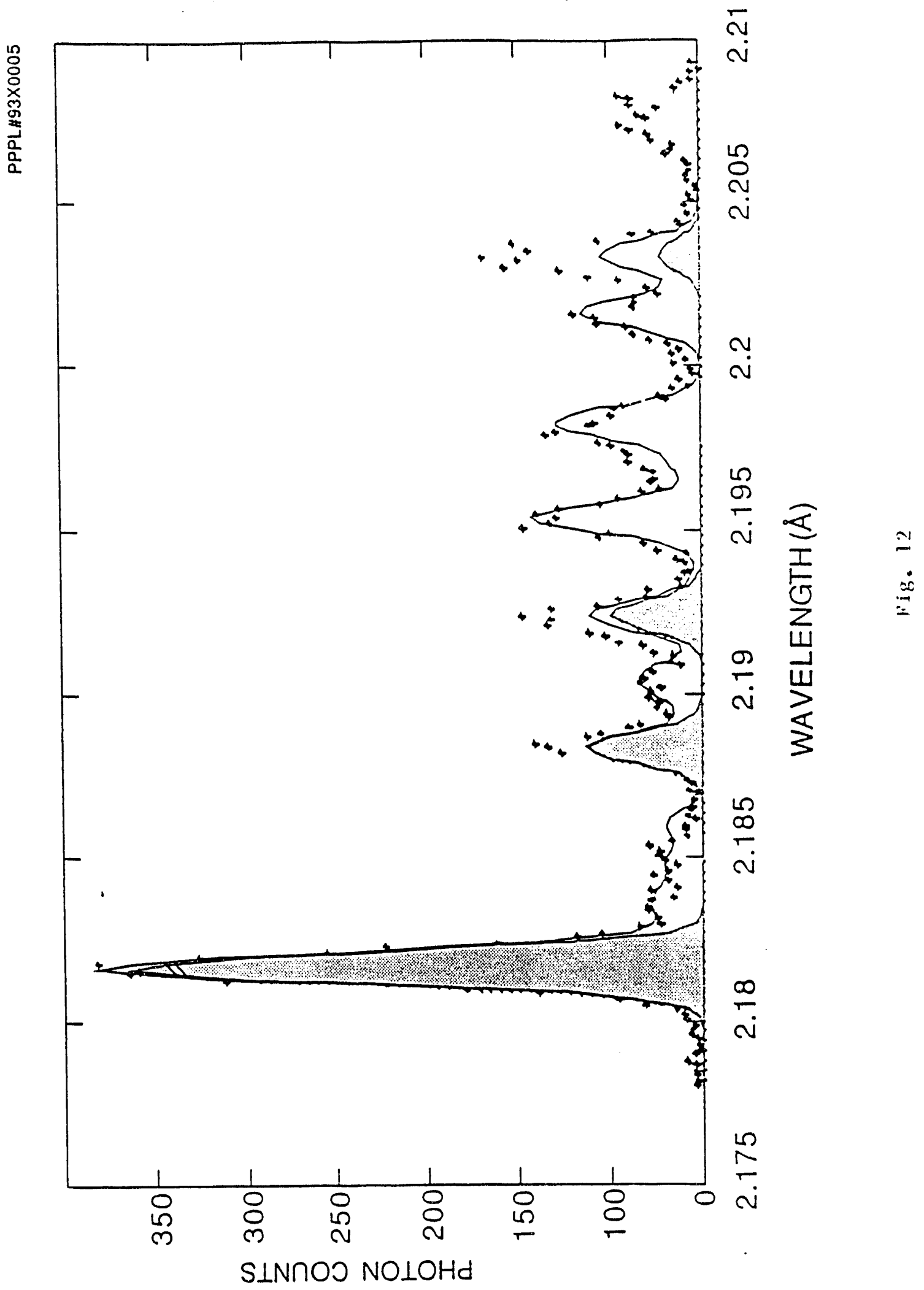


Dr. F. Peotoni, Univ, of Wollongong, AUSTRALIA

Prot. M.H. Brennan, Univ. of Syonoy. AUSTRALIA

Plasma Rosearch Leb., Austraten Nat Univ., AUSTRALIA

Prof. I.R. Jones, Flindors Univ. AUSTRALIA

Prof. F. Cap, Inst for Theoroticel Physics, AUSTRIA

Prot. M. Hoindiver, Instiut for Theoretiecto Physik, AUSTRIA

Prot. M. Gosecens, Aetronomisch InetituUt, BELGIUM

Ecole Roy de Milituin, Las. de Pry. Plasmas, BELGIUM

Commiscion-Europenen, DG. XII-Fusion Proo., BELGIUM

Prof. A. Boucigus, Rikeuniveraititi Gent, BELGIUM

Dr. P.H. Sakenaka, Instuto Faica, BPUZZL.

Inctivito Neciond Do Pecapiess Especisis-INPE, BRUZIL.

Documents Orion, Abonic Energy of Conuda Lid., CANADA

Dr. M.P. Bectynekj, MPB Technologies, Inc., CANADA

Dr. H.M. Skeragard, Univ. of Sackatchowen, CANADA

Prof. J. Teichmam, Univ. of Monired, CANADA

Prot. S.R. Sremiveam, Univ. of Celogry, CANADA

Prot. T.W. Johneton, INAS-Energie, CANADA

Dr. R. Botron, Contre canacion de fusion megndique, CANADA

Or. C.R. James., Univ. of Nberta, CANADA

Dr. P. Lukta, Komenektho Universitu, CZECHOSLOVAKIA

The Librevien, Culhan Leboratory, ENGLAND

Librery. R61, Ruthartord Appletion Leboratory, ENGLAND

Mrs. S.A. Hulchineon, JET Librey, ENGLAND

Or. S.C. Sheme, Uniw. of South Pecific, FWJI ISLANDS

P. Menonen, Univ. of Haleinki, FINLAND

Prot. M.N. Bunesec, Ecolv Potyruchnique., FRANCE

C. Moutrar, Lob. do Phycique des Milioux lonieds, FRANCE

J. Radat, CENCADARACHE - Bat S06, FRANCE

Prot. E. Economow, Univ. of Crew. GREECE

Mb. C. Rinni, Univ. of lominina, GREECE

Dr. T. Mul, Acadumy Exiloprephic Ser., HONG KONO

Proprint Librery, Hungerien Acadirmy of SC.. HUNGAAY

Dr. B. Descupte, Saha inset of Nuclaer Plycica, INDIA

Dr. P. Kew, Inst. for Plama Pescarch, INOU

Dr. P. Rocenew, lenwel inst of Technobogy, ISPAEL

Librerien, Invemational Cemer for Theo Phyeics, ITALY

Miss C. Do Palo, Alleociazions EURATOMENEA, ITALY

Dr. G. Groseo, Isviuto al Fieica ded Plasma, ITALY

Prot. G. Postenoni, latwio Gas lonizzed Del Cnr, ITALY

Or. H. Yomewo, Toahiba Res a Dowl Center, JAPAN
Prof. I. Kawakemi, Hirochima Univ., JAPAN

Prof. K. Nichikawa, Hiroshima Univ., LAPAN

Director, Jepen Alomic Enorgy Research Inst, JAPAN

Prot. S. Ibh, Kyushu Univ., JAPAN

Rosearch info. Cr., Nabions Instit. for Fusion Science. JAPAN

Prot. S. Tenaka, Kyolo Univ. JAPAN

Librery, Kyoto Univ., JAPAN

Prot. N. Inowe, Univ. of Tokyo. LAPAN

Secretary, Pleuma Saction, Electrowohnicel Lab., JAPAN

S. Mori, Technical Advieor, LAEPI, LAPAN

D. O. Mund, Kumemoso insl of Technology. JAPAN

J. Hyom-Sook, Korea Alomic Eneroy Rosearch Inst, KOAEA

D.I. Choi, The Korea Adv. Inst of Sal. \& Tech., KOAEA

Prof. B S. Lloy, Univ. of Wrikato, NEW ZEALAND

Inte of Phyica, Chinese Acad Sa PEOPLE'S REP. OF CHINA

Librey, Inat of Plaema Phyelos, PEOPLE'S REP. OF CHINA

Tainghua Univ. Librery. PEOPLE'S REPUBLIC OF CHINA

Z. U. S.W. Inat Phyeica, PEOPLE'S REPUBUC OF CHINA

Prot. J.A.C. Cabra, Inaturo Superior Tecnico, PORTUGAL

Dr. O. Potrus, Al I CUZA Univ., ROAMANIA

Dr. J. do Vitions, Fueion Studies, AEC, S. AFRICA

Prot. M.A. Hewberg, Univ. of Nated, S. AFRICA

Prot. D.E. Km. Poheno InEt. of Sai. \& Tech., SO. KOREA

Prot. C.I.E.MA.T, Fuaion Division Library, SPAN

Dr. L SImmio, Univ. of UMEA, SWEDEN

Libreny. Royd inat of Tectnology, SWEDEN

Prot. H. Wrindimecon, Chalmere Univ. of Tech., SWEDEN

Cemes Phys. Des Plasmas, Ecolo Polyluch, SWITZERLAND

Bibliothenk. Inat. Voor Plasma-Fyeica, THE NETHERLANDS

Aese Prot. Or. S. Cakir, Midds Eest Tech. Univ., TURKEY

Or. V.A. Cunthikh, Sal. Res. Inst. Enctrophys.I Apperatus, USSR

Dr. D.D. Pyurby, Siberien Brmach of Academy of Sai., USSR

Dr. O.A. Eisoev, I.V. Kurchatov Imst, USSR

Lbrerien, The Ukr.SSR Academy of Scionces, USSR

Dr. LM. Kowizhnykh, Inst. of Conerd Phyzica, USSA

Kemtonchungandepo GmbH, Zentrabibliothek, W. GERMANY

Bibliounck, Inst. For Plasmalorechung, W. GERMANY

Prot. K. Schinder, Ruhr-Universitu Bochum, W. GERMANY

Dr. F. Wegnex, (ASOEX), Max-Plenck-Inetitut, W. GERMANY

Librerien, Max-Plenck-Instien, W. GERMANY

Prot. R.K. Jenov, Inal of Phycios, rucosLaVIa 

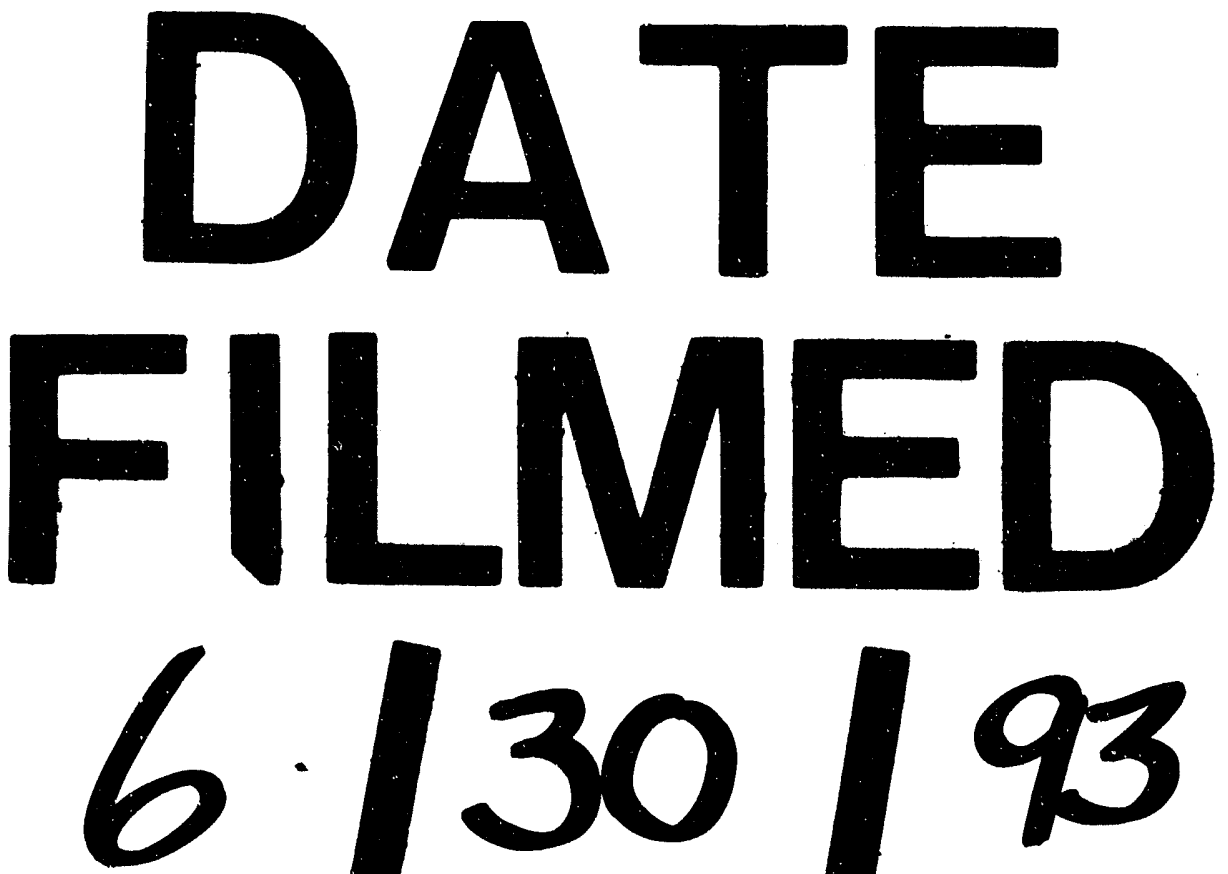

|30 |

93 
